\title{
Large Carbonate Associated Sulfate isotopic variability between brachiopods, micrite, and other sedimentary components in Late Ordovician strata
}

Theodore M. Present (corresponding author, ted@caltech.edu)

California Institute of Technology, MC 131-24, Pasadena, CA 91125, USA

Guillaume Paris (gparis@caltech.edu)

California Institute of Technology, MC 131-24, Pasadena, CA 91125, USA

Andrea Burke1(ab276@st-andrews.ac.uk)

California Institute of Technology, MC 131-24, Pasadena, CA 91125, USA

Woodward W. Fischer (wfischer@caltech.edu)

California Institute of Technology, MC 100-23, Pasadena, CA 91125, USA

Jess F. Adkins (jess@gps.caltech.edu)

California Institute of Technology, MC 131-24, Pasadena, CA 91125, USA

\section{Highlights}

- Isolated small amounts of different components from Late Ordovician limestones

- Measured texture-specific Carbonate Associated Sulfate (CAS) sulfur isotope ratio

- A range of $25 \%$ in CAS between components can explain bulk-rock CAS variation

- CAS from well-preserved brachiopod calcite preserves Ordovician seawater sulfate

- Variability of micrite and cement components reflects diagenetic processes

\footnotetext{
${ }^{1}$ Present address: University of St. Andrews, Irvine Building, St. Andrews, Fife KY16 9AL, United Kingdom
} 


\title{
Large Carbonate Associated Sulfate isotopic variability between brachiopods, micrite, and other sedimentary components in Late Ordovician strata
}

\author{
Theodore M. Present (corresponding author, ted@caltech.edu) \\ California Institute of Technology, MC 131-24, Pasadena, CA 91125, USA \\ Guillaume Paris (gparis@caltech.edu) \\ California Institute of Technology, MC 131-24, Pasadena, CA 91125, USA \\ Andrea Burke19ab276@st-andrews.ac.uk) \\ California Institute of Technology, MC 131-24, Pasadena, CA 91125, USA \\ Woodward W. Fischer (wfischer@caltech.edu) \\ California Institute of Technology, MC 100-23, Pasadena, CA 91125, USA \\ Jess F. Adkins (jess@gps.caltech.edu) \\ California Institute of Technology, MC 131-24, Pasadena, CA 91125, USA
}

\section{Highlights}

- Isolated small amounts of different components from Late Ordovician limestones

- Measured texture-specific Carbonate Associated Sulfate (CAS) sulfur isotope ratio

- A range of $25 \%$ in CAS between components can explain bulk-rock CAS variation

- CAS from well-preserved brachiopod calcite preserves Ordovician seawater sulfate

- Variability of micrite and cement components reflects diagenetic processes

\begin{abstract}
Carbonate Associated Sulfate (CAS) is trace sulfate incorporated into carbonate minerals during their precipitation. Its sulfur isotopic composition is often assumed to track that of seawater sulfate and inform global carbon and oxygen budgets through Earth's history. However, many CAS sulfur isotope records based on bulk-rock samples are noisy. To determine the source of bulk-rock CAS variability, we extracted CAS from different internal sedimentary components micro-drilled from well-preserved Late Ordovician and early Silurian-age limestones from Anticosti Island, Quebec, Canada. Mixtures of these components, whose sulfur isotopic compositions vary by nearly $25 \%$, can explain the bulk-rock CAS range. Large isotopic variability of sedimentary micrite CAS $\left({ }^{34}\right.$ S-depleted from seawater by up to $15 \%$ ) is consistent with pore fluid sulfide oxidation during early diagenesis. Specimens recrystallized during burial diagenesis have $\mathrm{CAS}^{34} \mathrm{~S}$-enriched by up to $9 \%$ from Hirnantian seawater, consistent with microbial sulfate reduction in a confined aquifer. In contrast to the other variable components, brachiopods with well-preserved secondary-layer fibrous calcite - a phase independently known to be the best-preserved sedimentary component in these strata-have a more homogenous isotopic composition. These specimens indicate that seawater sulfate remained close to about 25\% (V-CDT) through Hirnantian (end-Ordovician) events, including glaciation, mass extinction, carbon isotope excursion, and pyrite-sulfur isotope excursion. The textural relationships between our samples and their CAS isotope ratios highlight the role of diagenetic biogeochemical processes in setting the isotopic composition of CAS.
\end{abstract}

\footnotetext{
${ }^{1}$ Present address: University of St. Andrews, Irvine Building, St. Andrews, Fife KY16 9AL, United Kingdom
} 


\section{$44 \quad$ Keywords}

45 Multi-collector inductively coupled plasma mass spectrometry; MC-ICP-MS; sulfur isotopes;

46 Hirnantian; Silurian; diagenesis

47

\section{Graphical Abstract}
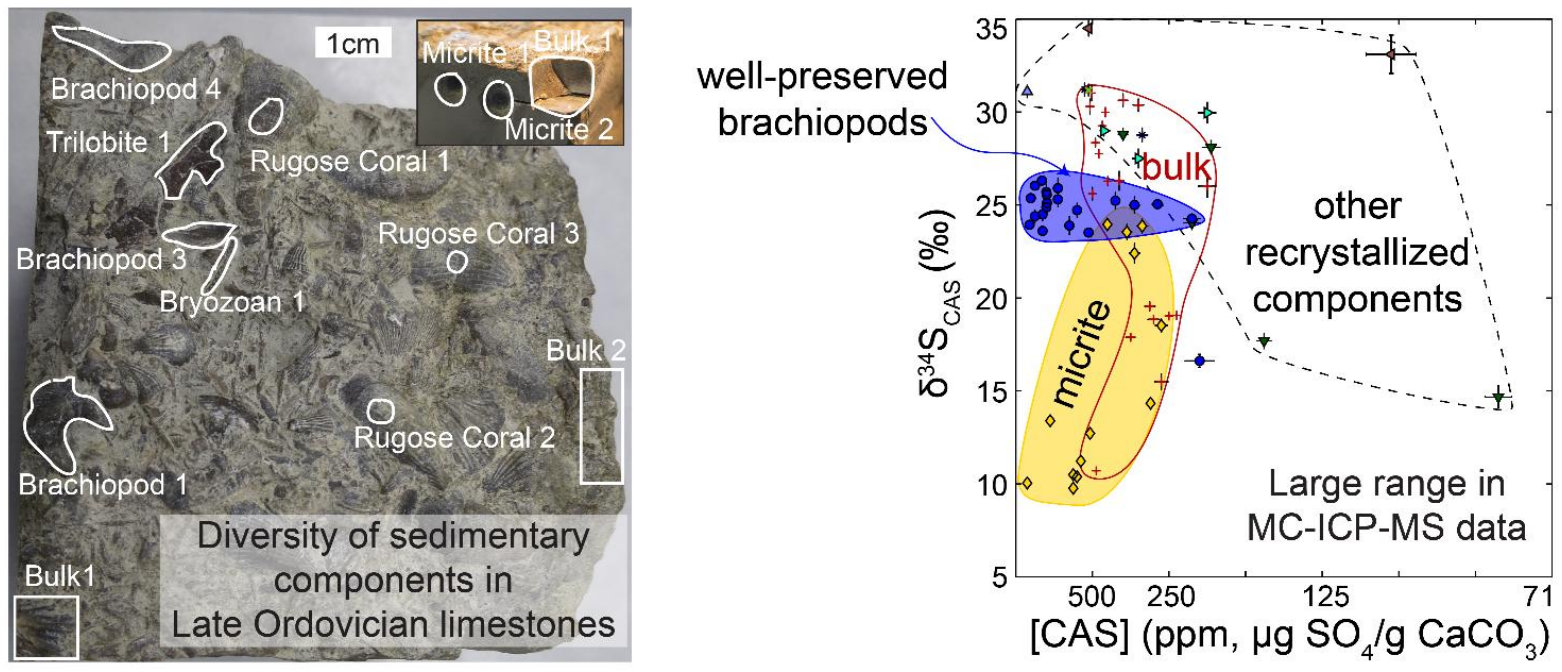


\section{Introduction}

The sulfur isotopic composition of Carbonate Associated Sulfate (CAS) is routinely measured as a proxy for the composition of ancient seawater sulfate and informs Earth's surface redox balance (Burdett et al. 1989; Kampschulte and Strauss 2004). CAS is trace sulfate commonly found in carbonate rocks of all ages (e.g. Burdett et al. 1989; Kah et al. 2004; Kampschulte and Strauss 2004; Paris et al. 2014a), and generally thought to be incorporated from ambient seawater during precipitation of carbonate phases (Burdett et al. 1989). Because carbonate strata are nearly ubiquitous in the geologic record, and carry abundant geological and geochemical context, CAS has the potential to provide a robust and high-resolution archive of changes in the sulfur cycle (Kampschulte and Strauss 2004).

Much effort has gone into constructing time-series records of marine sulfate's isotopic composition. Sulfur isotopic compositions are reported in the common $\delta^{34} \mathrm{~S}$ notation as part-perthousand (\%) deviations of ${ }^{34} \mathrm{~S} /{ }^{32} \mathrm{~S}$ relative to the Vienna Canyon Diablo Troilite (V-CDT) reference standard. Modern oceans constitute a large sulfur reservoir thought to be at steadystate between weathering and volcanic influxes and reduced and oxidized outputs (Bottrell and Newton 2006; Garrels and Lerman 1984). Sulfate reduction to sulfide is directly linked to the carbon cycle by microbial metabolisms, and a fraction of this sulfide flux is preserved as pyrite. There can be large kinetic sulfur isotope fractionations associated with microbial sulfate reduction (MSR), so the relative size of the pyrite sink can affect the isotopic composition of seawater (Garrels and Lerman 1984). Today, this conceptual model leads to an estimated 20 Myr residence time of sulfate in the ocean (Bottrell and Newton 2006), so longer-term changes in seawater $\delta^{34} \mathrm{~S}$ reflect the distribution of oxidized and reduced chemical species on Earth's 


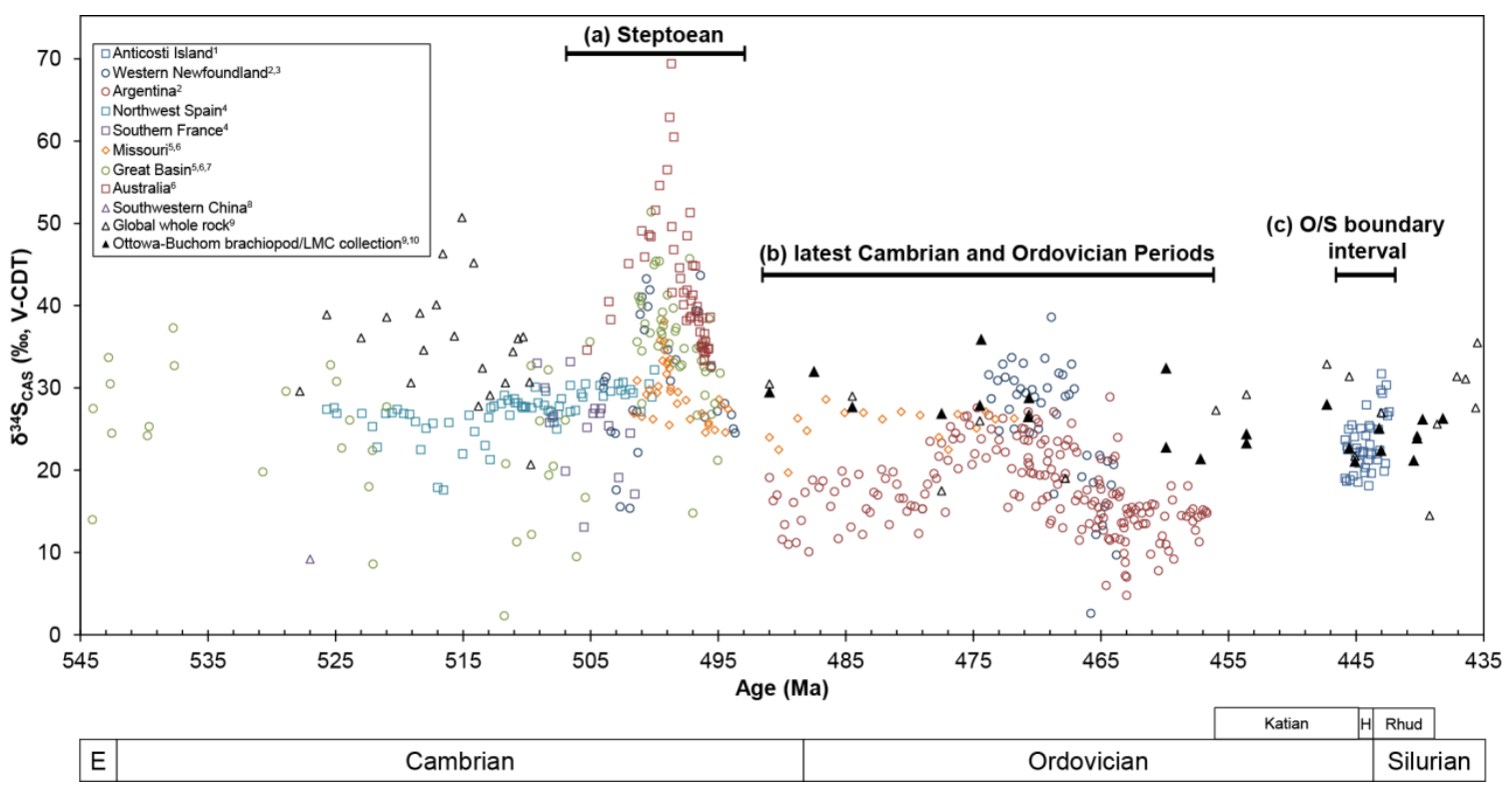

Figure 1: Compilation of previously reported CAS $\delta^{34} \mathrm{~S}$ values from early Paleozoic successions, plotted by sample collection location. Open symbols represent CAS extracted from bulk-rock (commonly micritic) samples, and closed symbols represent CAS extracted from biogenic calcite. See the text for discussion regarding the Steptoean Stage (a), the latest Cambrian and Ordovician periods (b), and the Ordovician-Silurian $(\mathrm{O} / \mathrm{S})$ boundary interval $(\mathrm{c}) . \mathrm{E}=$ Ediacaran, $\mathrm{H}=$ Hirnantian. $\mathrm{LMC}=$ low-magnesium calcite. Data references: ${ }^{1}$ Jones and Fike (2013), ${ }^{2}$ Thompson and Kah (2012), ${ }^{3}$ Hurtgen et al. (2009), ${ }^{4}$ Wotte et al. (2012b), ${ }^{5}$ Gill et al. (2007), ${ }^{6}$ Gill et al. (2011b), ${ }^{7}$ Loyd et al. (2012b), ${ }^{8}$ Goldberg et al. (2005), ${ }^{9}$ Kampschulte and Strauss (2004), ${ }^{10} \mathrm{Wu}$ et al. (2014).

Large stratigraphic CAS variability around longer-term trends may be primary, or be a result of secondary processes (Kampschulte and Strauss 2004). Primary CAS variability would reflect temporal changes in seawater sulfate, or spatial patterns between depositional settings or basins. Secondary processes involve incorporation of sulfate from post-depositional sources. These could include burial or dolomitizing fluids, diagenetically-modified pore fluids, or oxidation of other sulfur-bearing phases in the rock (Gill et al. 2008; Lyons et al. 2004; Marenco et al. 2008b; Rennie and Turchyn 2014). While secondary processes may mask the interpretation of sulfur isotopes in a global mass balance framework, they do contain additional information 
92 about the paleoenvironment and basin history. Finally, sample preparation itself might oxidize 93 sulfur-bearing phases in the rock and result in measurement of a mixture of CAS and newly 94 generated sulfate (Marenco et al. 2008a; Mazumdar et al. 2008; Wotte et al. 2012a). Previous workers have tried different methods to reduce the contribution of secondary processes. These methods include mathematically smoothing variability (e.g. Kampschulte and Strauss 2004; Song et al. 2014), selecting the most robust or best-preserved samples (e.g. fossils in Gill et al. 2011a; Kampschulte et al. 2001; Kampschulte and Strauss 2004; Newton et al. 2011) (filled triangles in Figure 1), chemically isolating CAS during extraction from other sulfurbearing phases (Wotte et al. 2012a), and applying independent geochemical indicators of preservation (Gill et al. 2011a; Goldberg et al. 2005). Other studies have hypothesized that high CAS variability mainly reflects the primary distribution of marine sulfate, especially in Precambrian and early Paleozoic strata (Gill et al. 2011b; Kah et al. 2004; Loyd et al. 2012b; Thompson and Kah 2012; Wotte et al. 2012b). The implication is that a small marine sulfate reservoir is necessary to explain observations of rapidly changing ( $<1 \mathrm{Myr}$ ) or spatially heterogeneous isotopic composition. For example, CAS datasets

107 from the late Cambrian Period include a large positive $\delta^{34} \mathrm{~S}$ excursion that coincides with the 108 Steptoean Positive Isotopes of Carbon Excursion (SPICE) event, but the magnitude of the excursion varies strongly between localities (interval "a" in Figure 1) (Gill et al. 2007; Gill et al. 2011b; Hurtgen et al. 2009). Similarly, latest Cambrian through Ordovician CAS records from 111 Argentinian strata show a large range of more than $10 \%$ over both short and long intervals, and display different trends from North American CAS records of the same age (interval " $\mathrm{b}$ " in

113 Figure 1) (Gill et al. 2007; Thompson and Kah 2012). 
To a certain extent, the ability to choose ideal samples for sulfur isotope analysis has been limited by the amount of sulfate required by traditional gas-source mass spectrometric methods. Typically, millimoles of sulfate, corresponding to tens of grams of Phanerozoic carbonates, are precipitated as barite and combusted (as summarized by Wotte et al. 2012a). Because many geologic successions do not offer texturally homogenous samples, traditional CAS analysis of such samples may thus integrate many different phases (primary grains, micrite, and cements of different age). A recent multi-collector inductively coupled plasma-source mass spectrometric (MC-ICP-MS) method for sulfur isotopic analysis of aqueous sulfate (Paris et al. 2013) facilitates the analysis of nanomole-level sulfur samples from $<10 \mathrm{mg}$ of typical Phanerozoic carbonates. Interval "c" (Ordovician-Silurian boundary interval) in Figure 1 shows a CAS record from texturally heterogeneous limestones collected on Anticosti Island, Canada (Jones and Fike 2013). This record has variability that is nearly half of the magnitude of secular changes over the entire Phanerozoic interval (Kampschulte and Strauss 2004; Wu et al. 2014) but is interpreted to reflect a constant seawater $\delta^{34} \mathrm{~S}$ composition during Late Ordovician time (Jones and Fike 2013). Near the end of Late Ordovician time there was a major climate change into a glaciated world, which coincides with the Late Ordovician Mass Extinction (LOME) - the second-largest Phanerozoic biotic crisis in terms of raw taxonomic losses (Finnegan et al. 2011; Finnegan et al. 2012). Globally correlated positive carbon isotope excursions and pyrite-sulfur isotope excursions coincide with peak glaciation and extinction (Gorjan et al. 2012; Hammarlund et al. 2012; Saltzman and Young 2005; Yan et al. 2009; Zhang et al. 2009) during the end-Ordovician Hirnantian Age (Gorjan et al. 2012; Hammarlund et al. 2012; Saltzman and Young 2005; Yan et al. 2009; Zhang et al. 2009). 
To understand the respective influences of primary and secondary processes in Anticosti

138 Island carbonates, we measured the CAS sulfur isotopes associated with the different

139 petrographic textures and sedimentary components in limestones from the same Anticosti Island

140 stratigraphic sections as Jones and Fike (2013). By exploring and understanding the variability

141 of CAS in such samples, we can point to a phase best recording primary variability. Therefore,

142 we can construct a more precise and accurate record of seawater sulfate, and begin to exploit the

143 information content of CAS measurements that relate to early diagenetic or burial processes.

\section{Geologic setting and samples}

Anticosti Island consists of nearly flat-lying exposures of Late Ordovician through lower

147 Silurian strata deposited on a Laurentian tropical carbonate ramp in the Taconic foreland

148 (Desrochers et al. 2010; Jones et al. 2011). During Late Ordovician time, growth of large ice

149 sheets on the southern hemisphere continent of Gondwana drove a marine regression

150 (Desrochers et al. 2010; Finnegan et al. 2011). This began in the Katian Age (453.0-445.2 Ma),

151 and peaked near the end of the Hirnantian Age (445.2-443.8 Ma), wherein clumped isotope

152 paleothermometry and extinction patterns suggest sharp marine cooling at tropical latitudes

153 (Finnegan et al. 2011; Finnegan et al. 2012). During this period, mixed carbonate-siliciclastic

154 facies representing near-shore environments were deposited on the eastern sector of the island,

155 and carbonate-dominated facies representing more offshore environments were deposited further

156 west (Copper et al. 2013; Desrochers et al. 2010; Jones et al. 2011). These strata are in the

157 Vauréal, Ellis Bay, and Becsie formations (Figure 2) that, due to subsidence associated with

158 Taconic Orogeny flexure, contain no major unconformities (Desrochers et al. 2010). On the

159 basis of biostratigraphy and chemostratigraphy, the Ordovician-Silurian boundary is thought to 
lie near the top of the Ellis Bay Formation, which mainly consists of bioturbated and nodular thinly bedded limestones and calcareous shales; higher-order cycles in the eastern sector grade up to sandstones (Copper et al. 2013; Desrochers et al. 2010). The uppermost member of the Ellis Bay Formation, the Laframboise Member, consists of oncolitic grainstones overlain in the more distal western sector by calcimicrobial-coral bioherms and hummocky cross-stratified amalgamated sands and grainstones (Copper et al. 2013; Desrochers et al. 2010).
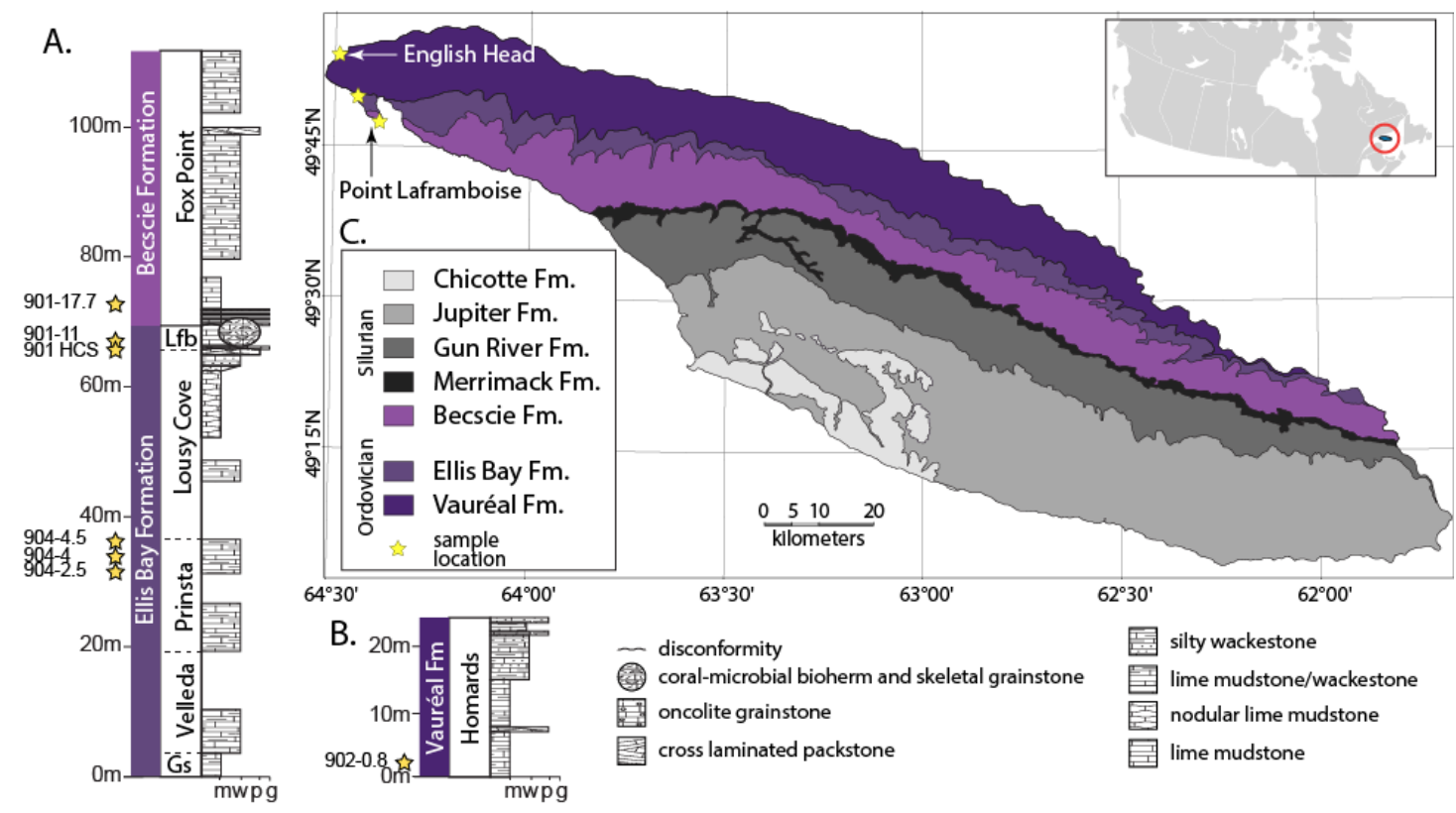

Figure 2: Stratigraphic logs and map of Ordovician and Silurian-age strata on Anticosti Island modified from Jones et al. (2011) after Desrochers and Gauthier (2009). Stars mark locations of stratigraphic sections on the western sector in this study. (A) Composite stratigraphic column of measured sections from Point Laframboise. Gs $=$ Grindstone Member, Lfb $=$ Laframboise Member, $\mathrm{m}=$ mudstone, $\mathrm{w}=$ wackestone, $\mathrm{p}=$ packstone, $\mathrm{g}=$ grainstone. (B) Stratigraphic column from English Head. There is approximately $150 \mathrm{~m}$ of strata from the top of the English Head section to the bottom of the Point Laframboise section (Jones et al. 2011). Fm. = formation. (C) Map of geologic formations exposed on Anticosti Island, which is in northeastern Quebec, Canada (inset). Limestones on Anticosti Island are exceptionally well-preserved: dolomitization is rare, primary sedimentary textures are retained, and the rocks experienced little burial alteration (Al- 
179 Aasm and Veizer 1982; Jones et al. 2011; Rohrssen et al. 2013). Trace element and clumped 180 isotope proxies for diagenetic alteration of carbonates indicate that sections on the western side 181 of the island are better preserved than on coeval sections in the east; this sector has the lowest 182 clumped isotope equilibration temperatures, and the least evidence for significant burial or 183 meteoric diagenesis overprint (Finnegan et al. 2011). Low-magnesium calcite (LMC) brachiopods - especially the secondary-fibrous layer of their shells — are exceptionally wellpreserved (Al-Aasm and Veizer 1982; Came et al. 2007; Finnegan et al. 2011). Limestone samples used in this study come from stratigraphic sections outlined in Finnegan et al. (2011). From this collection, we sampled seven stratigraphic horizons in the Vauréal, Ellis Bay, and Becsie Formations from the well-preserved western sector of Anticosti Island between English Head and Point Laframboise (stars on Figure 2). We intentionally selected heterogeneous limestone hand-samples (classified in Supplemental Data Table 1) in order to examine CAS variability on a small spatial scale that may be integrated by traditional

192 CAS extraction techniques. We targeted specific sedimentary components from the bulk-rock samples, including micrite, brachiopods, bryozoans, rugose corals, tabulate corals, trilobites, crinoids, and cements (Figure 3 and Supplementary Figure 1). Specifically, micritic samples came from calcimudstones or wackestones; these lithologies include variable amounts of skeletal fragment allochems, disseminated anhedral pyrite, minor framboidal pyrite, and minor quartz (Figure 4A,C,D). Micrite samples from sample 901-HCS are dolomitic wackestones, and are some of the only dolomitized rocks on Anticosti Island (Jones et al. 2011). Brachiopod shells retain much of their primary textures (Finnegan et al. 2011), although some regions are recrystallized (Figure 4B) or have minor pyrite ingrowth (Figure 4D). Because many of our analyses targeted fossil brachiopods, to explore potential vital effects (Burdett et al. 1989; 
202 Kampschulte et al. 2001; Paris et al. 2014b) we also analyzed the CAS isotopic composition of a

203 modern punctate brachiopod valve (Terebratalia transversa Sowerby) collected at the San Pedro

204 jetty, Los Angeles County, California and obtained from the Tremper-Long Beach State

205 Collection.

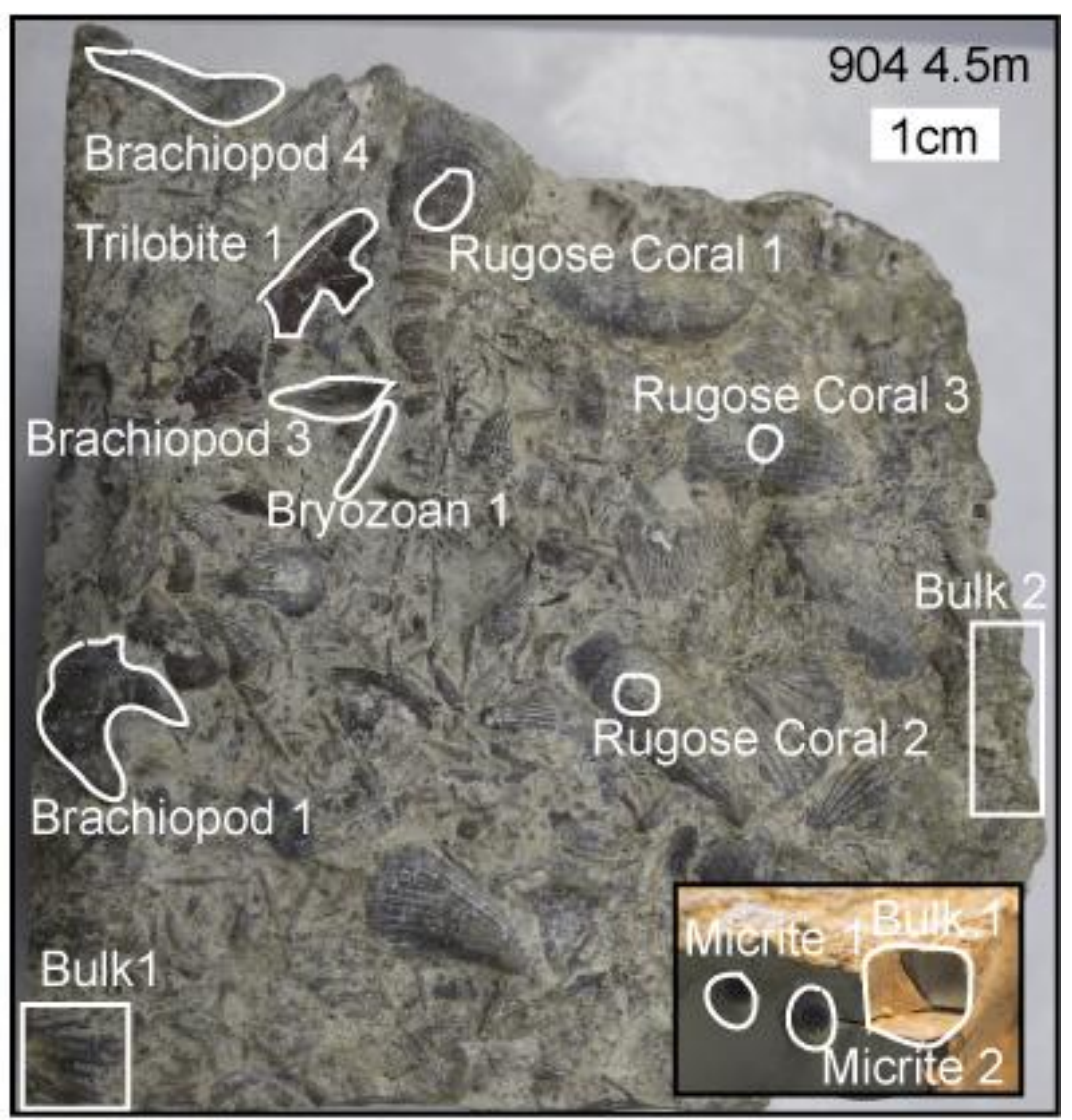

207 Figure 3: Sample 904-4.5m with the location of analyzed CAS specimens drilled, cut, or picked 208 from a skeletal packstone horizon. Analyzed specimens from the other six hand-samples are 209 shown in Supplemental Figure 1. 

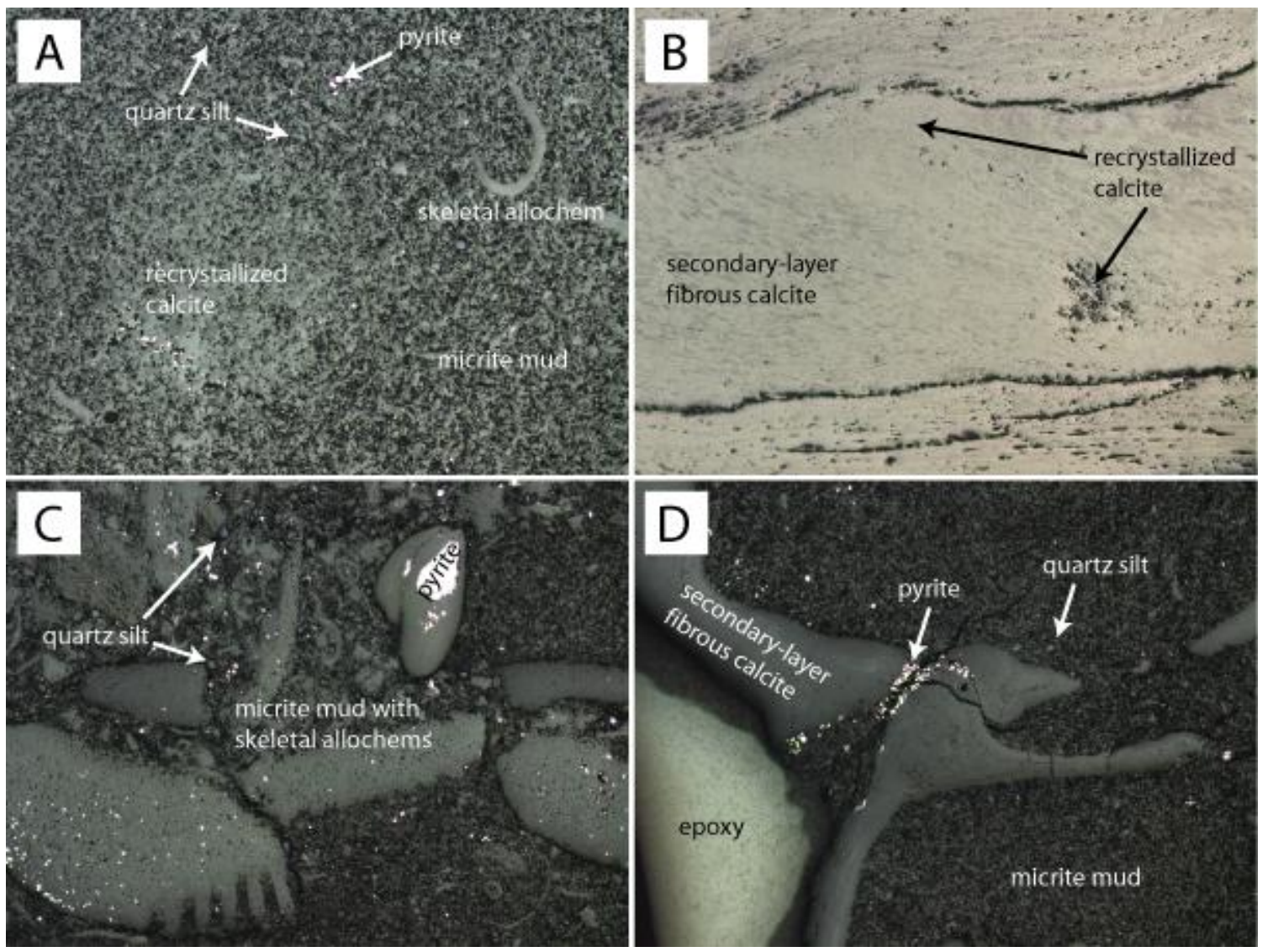

212 Figure 4: Plane polarized reflected light images of polished thick sections. Width of field of 213 view is about $2.4 \mathrm{~mm}$. (A) Sample 904-2.5 m, calcimudstone with minor quartz silt (purple214 gray), disseminated pyrite (bright yellow/white) and a skeletal fragment. (B) Fibrous calcite from the secondary layer of specimen Brachiopod 1 from Sample 904-2.5 m. The beige and gray banding is bireflectance of $\sim 50 \mu \mathrm{m}$-long calcite fibers, indicative of well-preserved biogenic lowmagnesium calcite. Note that some regions can still be recrystallized. (C) A particularly allochem-rich horizon in Sample 904-4 m with minor quartz silt and disseminated pyrite. Some skeletal grains are partially pyritized. (D) The cardinal process (the junction of the two valves) of specimen Brachiopod 3 from Sample 904-4 m with well-preserved fibrous calcite. Disseminated pyrite, possibly framboidal, is localized between the brachiopod valves.

\section{Methods}

Hand-samples were ultrasonicated in tap water followed by deionized water for 4 hours each, and dried in a $\sim 75^{\circ} \mathrm{C}$ oven. We prepared bulk-rock powders by homogenizing $\sim 1 \mathrm{~cm}^{3}$ of limestone with a mortar and pestle. Micrite, rugose coral, and tabulate coral specimens were 
milled with a $1 \mathrm{~mm}$ drill bit. Using a dental pick beneath a dissecting microscope, we picked 5-

$22810 \mathrm{mg}$ specimens of all other sedimentary components. Flakes of these components (but not the

229 milled components) were inspected under higher magnification to avoid matrix material, pyrite,

230 or oxide inclusions (Cummins et al. 2014). Brachiopod specimens were inspected to include

231 only optically transparent secondary-layer fibrous calcite (with the exception of one

232 recrystallized small specimen in sample 901-HCS, which we analyzed nonetheless). For some

233 brachiopod specimens, scanning electron microscope images were obtained at the Caltech

234 Geological and Planetary Sciences Division Analytical Facility (ZEISS 1550VP Field Emission

235 SEM using a $15 \mathrm{kV}$ accelerating voltage and $8 \mathrm{~mm}$ working distance) to examine the extent of

236 recrystallization and ensure there were no microscopic sulfide or oxide inclusions (Figure 5 and

237 Supplementary Figure 2). Such inclusions were never observed in any specimen under the

238 dissecting microscope or in the electron micrographs.
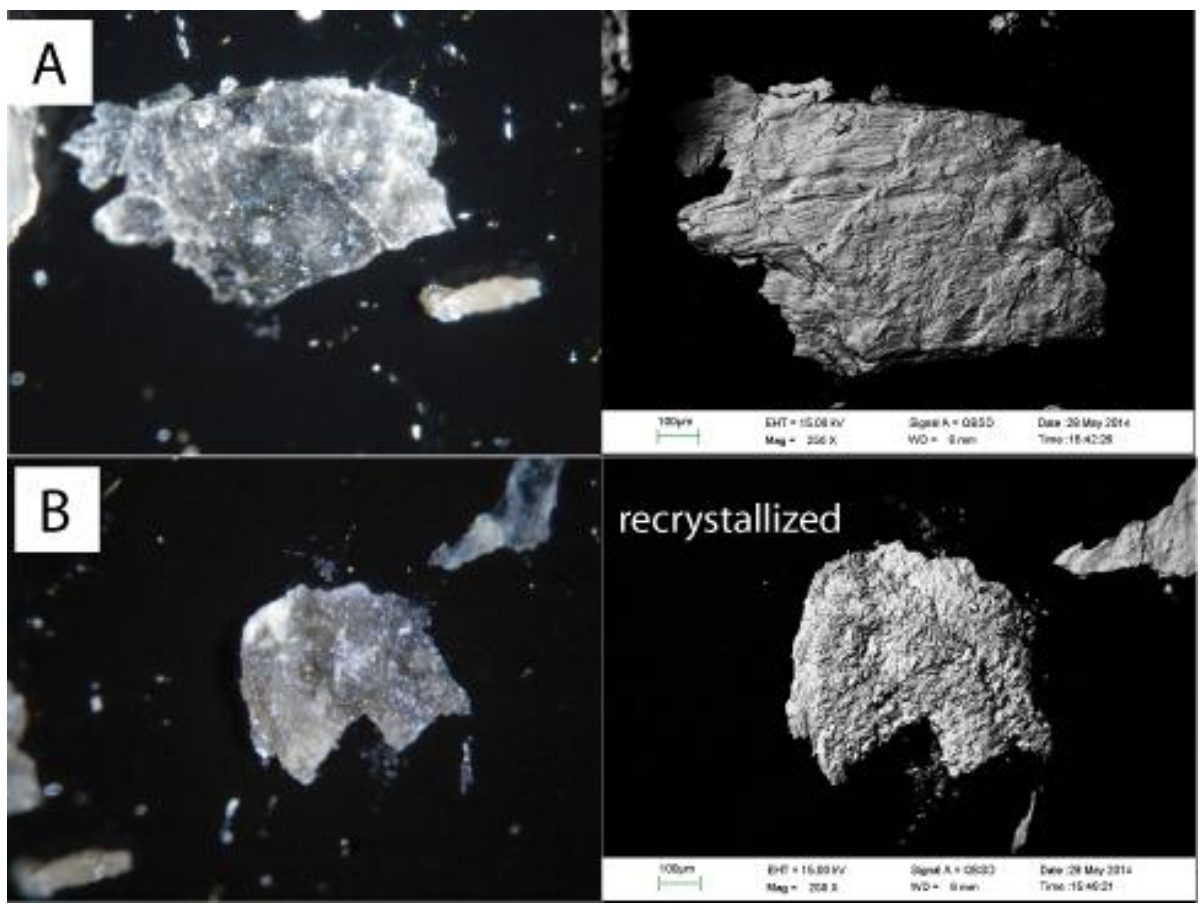

240 Figure 5: Binocular microscope (left) and electron microscope backscatter intensity (right) 241 images of two representative flakes picked from Brachiopod 1 from Sample 904-2.5m. Metal 
oxides or sulfides would show up as extremely bright spots in the electron microscope images. (A) A well preserved flake. The lineations are fibers of well-preserved secondary layer calcite; the best-preserved secondary layer fibrous calcite is optically clear. (B) A poorly-preserved flake excluded from analysis. When diagenetically altered, the fibrous calcite recrystallizes to fine equant grains and often turns yellow-brown. More examples of representative flakes that were included in specimens for CAS analyses are shown in Supplemental Figure 2.

To accurately measure trace sulfate in such small specimens (less than $255 \mathrm{nmol}$, typically 30-50 nmol sulfate), we minimized and tracked procedural blanks (i.e., contamination by sulfate from the laboratory, on the order of $0.3 \mathrm{nmol}$ ). After picking, specimens were handled in laminar flow benches in acid-cleaned vials and introduced only to $18.2 \mathrm{M} \Omega$-cm water (Millipore Milli-Q) or trace-metal pure reagents (Seastar Baseline).

Specimens were pre-cleaned prior to dissolution by ultrasonicating for $>4 \mathrm{hr}$ in $1 \mathrm{~mL}$ $10 \%(\mathrm{w} / \mathrm{w}) \mathrm{NaCl}$ solution and rinsing three times in $1 \mathrm{~mL}$ water, centrifuging and removing the supernatant between each rinse. In a clean vial, specimens were dissolved in $500 \mu \mathrm{L} 0.5 \mathrm{~N} \mathrm{HCl}$ for 4-12 hours while agitated on a shaker table, and then centrifuged. The supernatant was aliquoted for sulfate concentration analysis and sulfur isotopic composition analysis. Sulfate concentrations are reported in parts-per-million (ppm) by mass and exclude the weight of insoluble residue. This is equivalent to micrograms of sulfate per gram of acid-soluble rock, which we assume is calcite.

To ensure that our pre-cleaning or dissolution protocol does not influence the sulfurbearing phases extracted from the specimen, we tested different protocols on multiple powder aliquots from bulk-rock samples. For some aliquots, we neglected the $\mathrm{NaCl}$ leach steps. For others, we added an oxidative leach step after the $\mathrm{NaCl}$ rinse step. Oxidative leaching involved ultrasonicating in $1 \mathrm{~mL}$ of a $1: 1$ solution of $2 \mathrm{M} \mathrm{NaOH}$ and $30 \% \mathrm{H}_{2} \mathrm{O}_{2}$ for $10 \mathrm{~min}$ and then in methanol for $10 \mathrm{~min}$, and centrifuging and removing supernatant between steps. This was done three times before completing pre-cleaning with three water rinses as with other powders. To 
extract total sulfur as sulfate, some of these powder aliquots were dissolved for 4 hours in aqua regia (3:1 concentrated $\mathrm{HCl}$ and $\left.\mathrm{HNO}_{3}\right)$.

A specific concern is potential oxidation, by oxygen or ferrous iron, of reduced sulfur during dissolution. We tested our CAS extraction protocol on $10 \mathrm{mg}$ mixtures of powdered deep-sea coral (Desmophyllum dianthus SS0108-STA011 collected in January 2008 off Tasmania) and pyrite "CIT-12021" (Huanazala Mine, Caltech Mineralogy Collection). The coral samples came from two halves of one skeleton initially covered with an iron-manganeseoxide crust. The first half was ground with a mortar and pestle and sieved to $63-250 \mu \mathrm{m}$, with the crust, to mimic the presence of iron oxides in ancient limestones. The crust was abraded from the second half, which was then ground, treated for 11 hours in a 1:1 mixture of $2 \mathrm{M} \mathrm{NaOH}$ and $30 \% \mathrm{H}_{2} \mathrm{O}_{2}$, rinsed four times with water, dried, and sieved. The $\delta^{34} \mathrm{~S}$ composition of the pyrite is $1.08 \pm 0.35 \%$ o ( 1 s.e., $n=8)$, determined by combustion in a Costech elemental analyzer with a Thermo Delta-S isotope ratio mass spectrometer (IRMS). The coral and coral/pyrite mixtures were then pre-cleaned following the $\mathrm{NaCl}$ and water rinse protocol and dissolved for 4 hours in $0.5 \mathrm{~N} \mathrm{HCl}$. Another chunk from the abraded coral half was rinsed four times in water, dried, sieved, and dissolved in $10 \% \mathrm{HClO}_{4}$ without any pyrite.

To investigate vital effects in the modern brachiopod, we cut the sample into four subsamples with a razor. The specimens were pre-cleaned with the $\mathrm{NaCl}$ and water rinse protocol. We released CAS with $0.5 \mathrm{~N} \mathrm{HCl}$ from two specimens, and released total sulfur with aqua regia from the others. We expect the aqua regia digestion to release organically coordinated sulfur and inform any difference between CAS and organic sulfur. We are able to analyze such small amounts of sample powder (5-10 mg of limestone) with a new analytical technique that requires $\sim 5 \mathrm{nmol}$ of sulfate (Paris et al. 2013), which is 
292 about three orders of magnitude less sample than traditional IRMS techniques. We determined

293 sulfate concentrations by ion chromatography (Dionex ICS-2000, using an AS-19 column and 20

$294 \mathrm{mM} \mathrm{KOH}$ eluent at the Caltech Environmental Analysis Center). We used anion exchange

295 chromatography to purify sulfate from the remaining dissolved carbonate (Paris et al. 2014a) to

296 analyze in duplicate as aqueous sodium sulfate by MC-ICP-MS on a Thermo Scientific Neptune

297 Plus at Caltech (described previously by Paris et al. 2013). Specimens were prepared and

298 analyzed in sets of 12-16, and always along with 2-4 procedural blanks, 2 replicates of an in-

299 house dissolved deep-sea coral consistency standard, and 2 replicates of seawater.

The long-term $\delta^{34} \mathrm{~S}$ reproducibility of $\sim 18 \mathrm{nmol}$ sulfate replicates from the coral

consistency standard is $0.35 \%$ ( 1 s.d., excluding one $>5$ s.d. outlier) and is $0.13 \%$ ( 1 s.d.,

excluding one $>8$ s.d. outlier) for $\sim 280 \mathrm{nmol}$ sulfate replicates of seawater. The precision of

isotope measurements reported here is a combination of instrument stability, short-term reproducibility of the same sulfate solution, and variability of the procedural blank composition and amount. Procedural blanks were $0.32 \pm 0.24 \mathrm{nmol}(1 \mathrm{s.d}$.) sulfate with an isotopic composition of $\delta^{34} \mathrm{~S}=2.6 \pm 0.49 \%$ V-CDT. Blank correcting specimens typically increased their isotopic composition by 0.1 to $0.3 \%$. Reproducibility of sulfate concentration measurements is typically 3-5\% (1 relative s.d.), based on reproducibility of diluted seawater and dissolved coral triplicates run alongside specimens in each analytical session. We determined the carbonate carbon and oxygen isotopic composition of samples that had remaining flakes or powder after CAS extraction. Approximately 100-250 $\mu \mathrm{g}$ of the sample were accurately weighed into $10 \mathrm{~mL}$ glass vials, flushed with helium, dissolved for 1 hour at $75^{\circ} \mathrm{C}$ in $\sim 200 \mu \mathrm{L}$ concentrated $\mathrm{H}_{3} \mathrm{PO}_{4}$, and analyzed with a Thermo Gasbench autosampler and Thermo Delta V IRMS. Reproducibility of two in-house carbonate reference standards is better 
315 than $0.06 \%$ ( $1 \sigma$ s.e.) for $\delta^{13} \mathrm{C}$ and $0.23 \%$ o $(1 \sigma$ s.e. $)$ for $\delta^{18} \mathrm{O}$. Carbon and oxygen isotopic

316 compositions are reported relative to the Vienna Pee Dee Belemnite (V-PDB) carbonate

317 reference.

4. Results

The modern brachiopod we analyzed has an average CAS concentration of

Data Table 1). There is no isotopic difference between the extracted CAS and the total sulfur extracted with aqua regia.

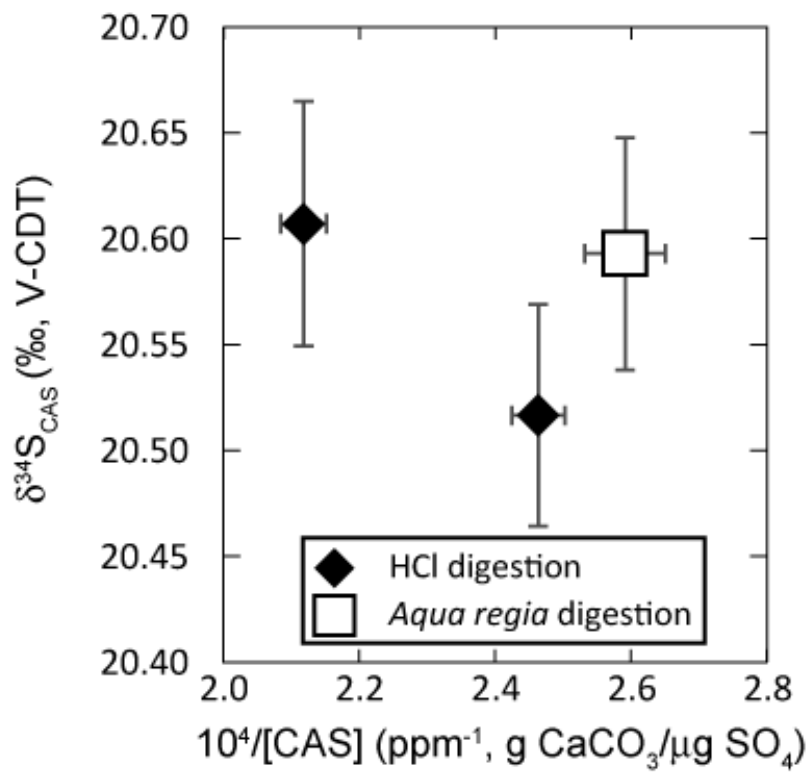

Figure 6: Composition of sulfate extracted by $0.5 \mathrm{~N} \mathrm{HCl}$ and aqua regia from a single valve of the modern brachiopod $T$. transversa collected in southern California. For reference, modern seawater sulfate is $21.15 \pm 0.15 \%$ o (Johnston et al. 2014). 
331 pre-cleaning protocol, vary between $11 \%$ and $21 \%$ (Figure $7 \mathrm{~A}$ ). Generally, sulfate extracted 332 from aliquots exposed to the oxidative leach is isotopically lighter than specimens exposed to 333 only the $\mathrm{NaCl}$ leach or only the water rinsing, and is less concentrated. This would be consistent 334 with pre-cleaning removing a ${ }^{34}$ S-enriched phase. However, we had poorly homogenized the 335 bulk-rock powder by mortar and pestle (Figure 7B), so we repeated the pre-cleaning experiment 336 with sample 904-4. In this case, the bulk-rock specimen was carefully homogenized (Figure 337 7D). Aliquots of sample 904-4, with any pre-cleaning protocol, showed less isotopic variability 338 (between 28\% and 31\%, Figure 7C) than aliquots of sample 901-HCS. In both samples, the 339 total variability among bulk-rock aliquots with any pre-cleaning protocol is less than the 340 variability between sedimentary components treated with the same $(\mathrm{NaCl}$ leach and water rinses only) pre-cleaning protocol. 

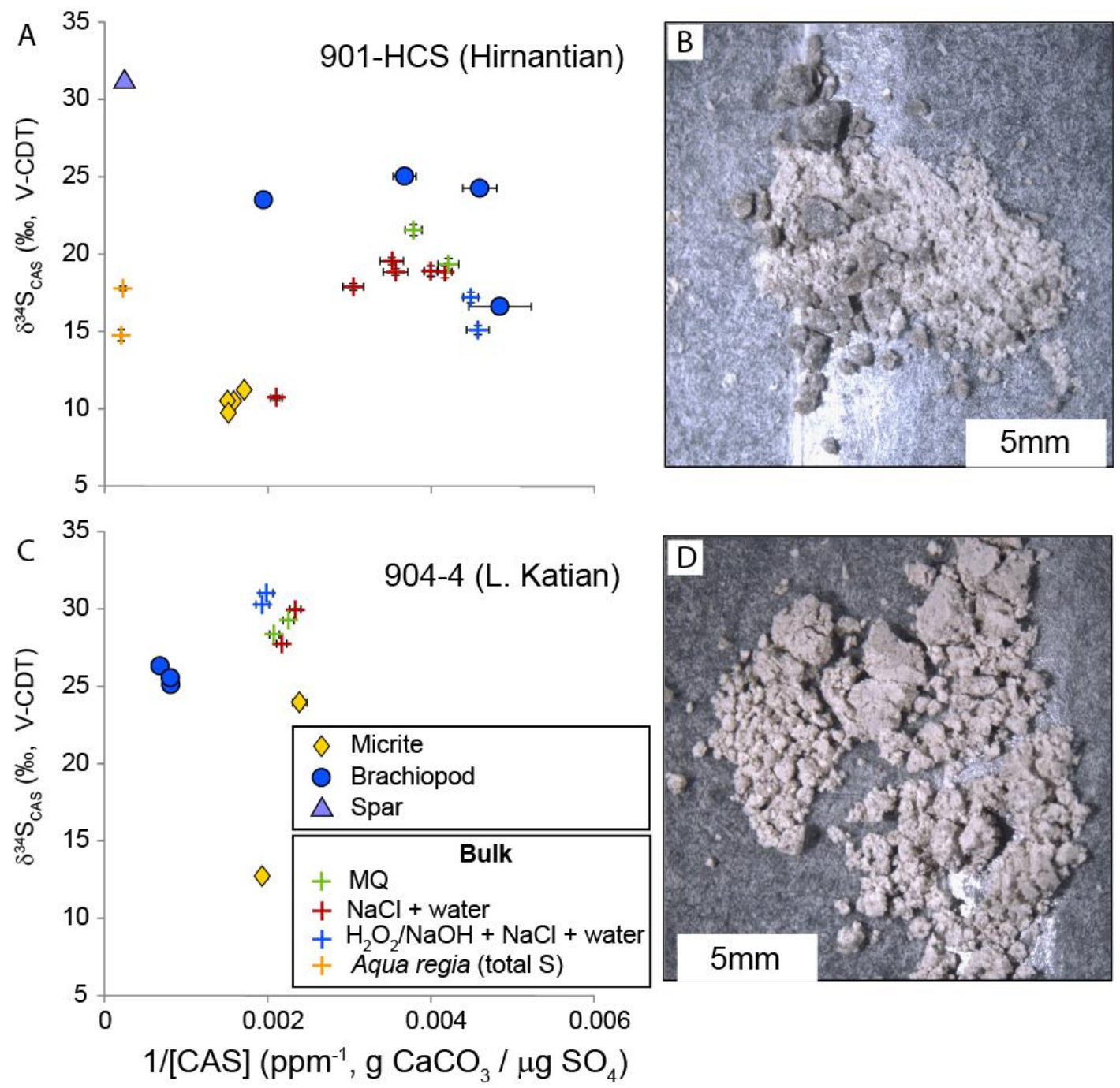

Figure 7: Plots of isotopic composition against inverse concentration for cleaning tests performed on two bulk-rock samples (plusses) and the associated texture-specific specimens (filled symbols). Colors of the bulk-rock data correspond to the extraction pre-cleaning and digestion protocol. (A) Isotopic composition and concentration of extracted sulfate from hand-sample 901-HCS. (B) Poorly homogenized sample powder from hand-sample 901-HCS. (C) Isotopic composition and concentration of extracted sulfate from hand-sample 904-4m. (D) Well homogenized sample powder from hand-sample 904-4m lacks the large dark gray chunks visible in panel B.

Results of the coral and pyrite dissolution experiments, using the $\mathrm{NaCl}$ and water precleaning protocol, are presented in Figure 8 and tabulated in Supplemental Data Table 2. The 
coral without any iron-manganese oxide crust has a CAS concentration of $4923 \pm 456 \mathrm{ppm}$ (1 s.d.)

355 and a $\delta^{34} \mathrm{~S}$ of $22.38 \pm 0.56 \%$ ( 1 s.d.). The coral with the iron-manganese oxide crust has a CAS

356 concentration of $3950 \pm 554 \mathrm{ppm}$ ( 1 s.d.) and a $\delta^{34} \mathrm{~S}$ of $22.39 \pm 0.11 \%$ ( 1 s.d.). These values are

357 consistent with the range of deep-sea coral measurements analyzed with other cleaning and

358 dissolution protocols (gray box in Figure 8, data in Supplemental Data Table 3). All coral/pyrite

359 mixtures (i.e. both with and without ferrous iron) except one had indistinguishable sulfate

360 concentrations and compositions from this range.

361 

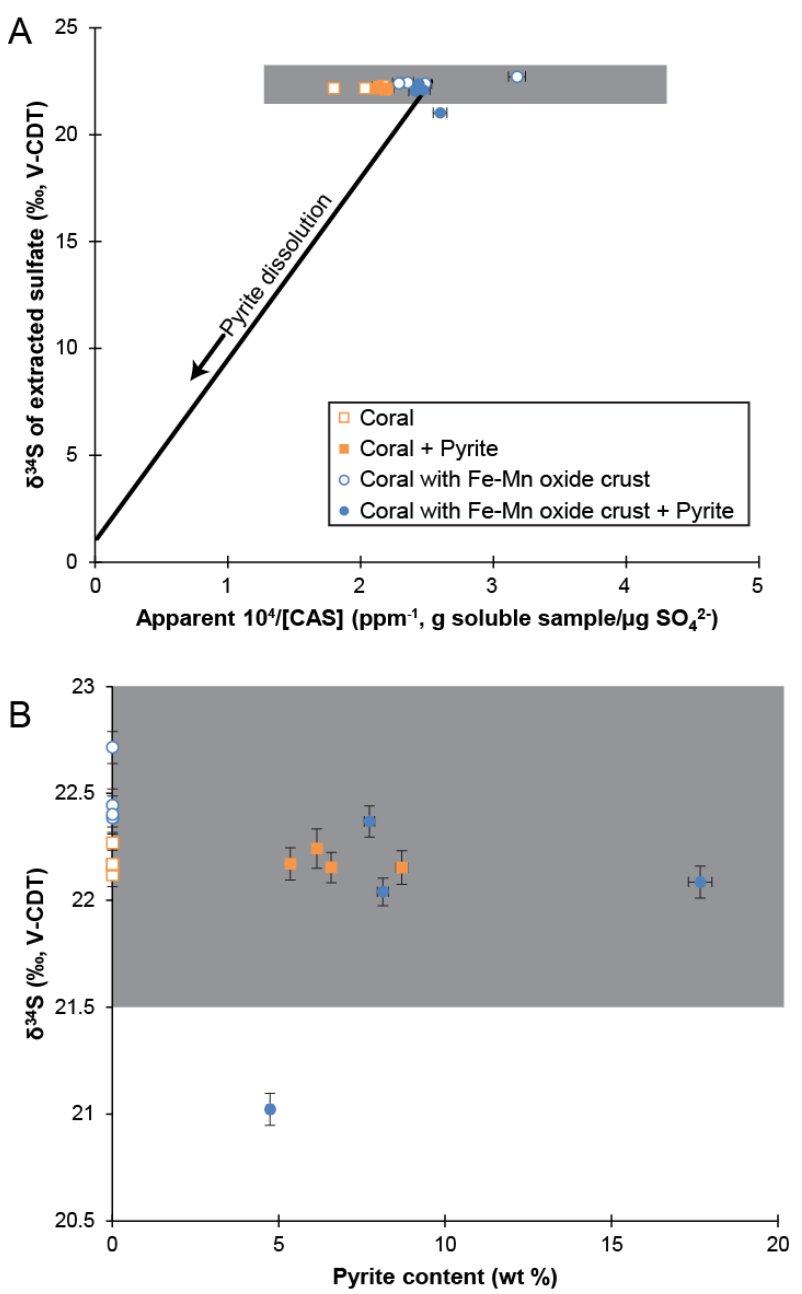

Figure 8: Apparent CAS compositions from deep-sea coral specimens intentionally mixed with pyrite, plotted with $1 \sigma$ standard error bars. (A) Apparent CAS isotopic composition plotted against inverse apparent CAS concentration. The gray field is the total range of CAS concentrations and isotopic compositions determined from the same coral polyp, but with different cleaning and dissolution protocols (see Supplemental Data Table 3). The black vector represents the expected trend from mixing pure pyrite with the average coral composition. (B) Apparent CAS isotopic composition plotted as a function of the amount of pyrite added to the samples. The gray field is the total range of coral CAS isotopic compositions as in panel A. 
concentration provide a natural space to examine possible mixing relationships between different textures. In this plot, binary mixtures would fall on a straight line.

The carbon and oxygen isotope compositions of remaining sample powders or flakes are tabulated in Supplemental Data Table 1 and plotted against CAS sulfur isotopic composition in

379 Supplemental Figure 3. Carbon isotope values vary systematically between 0.29 and $3.56 \%$ (VPDB) with stratigraphic height through the Hirnantian carbon isotope excursion, and are not correlated with sulfur isotope values. Similarly, oxygen isotope ratios range between -4.29 and 2.22\% (V-PDB), and overlap with the oxygen isotope data reported by Jones et al. (2011).

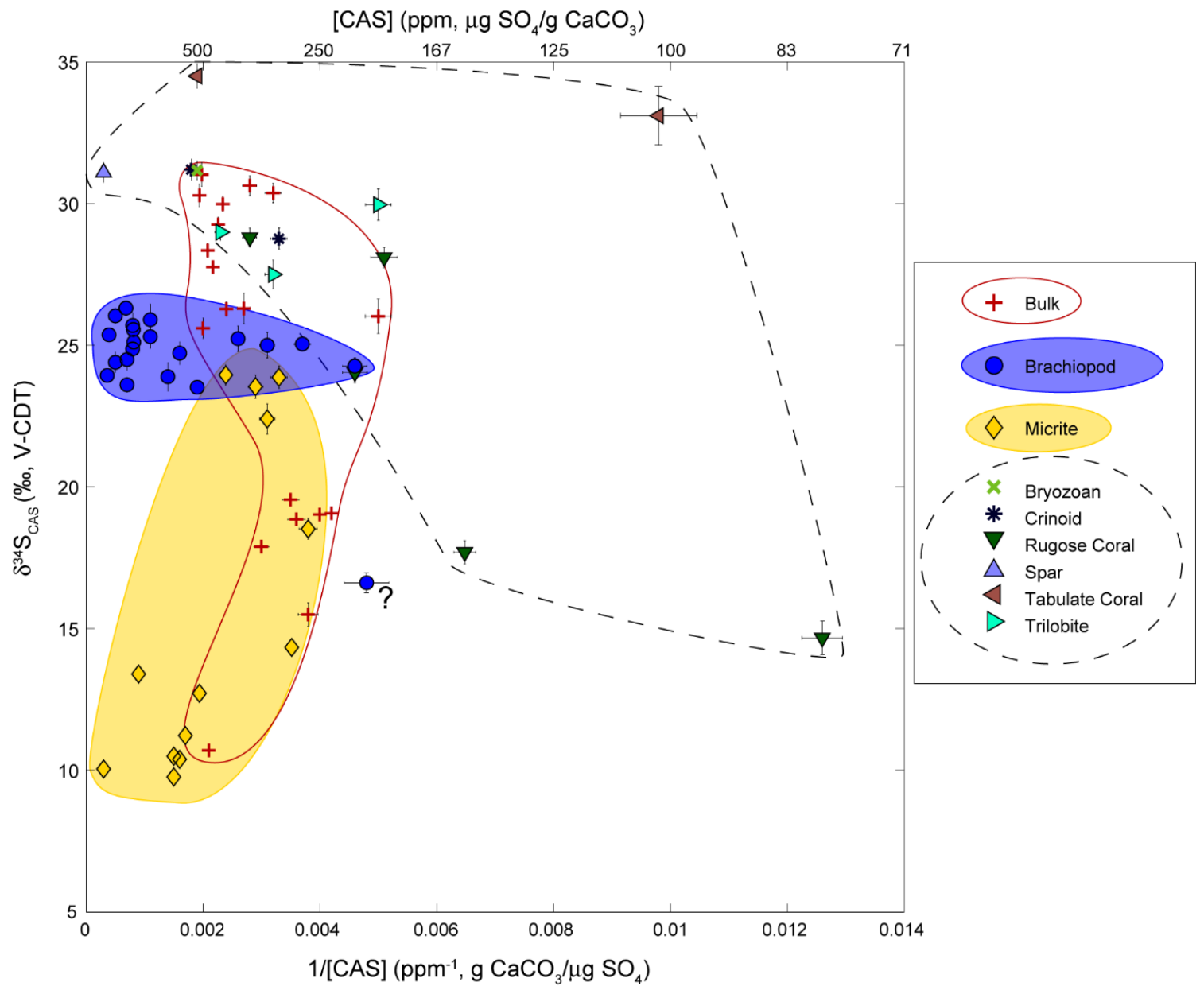

384 Figure 9: Cross-plot of CAS isotopic composition and inverse concentration with $1 \sigma$ standard 385 errors for all Anticosti Island specimens analyzed in this study and pre-cleaned by the $\mathrm{NaCl}+$ 
water rinsing method. The question mark notes the outlying, poorly preserved brachiopod specimen from sample 901-HCS.

\section{Discussion}

The total sulfur isotopic range of CAS we analyzed from different petrographic textures in Anticosti Island limestones is $25 \%$. This is nearly as large as the observed range in all Phanerozoic CAS data, which typically varies between about 10\%o and 40\%o (Kampschulte and Strauss 2004; Wu et al. 2014). We first assess if artifacts during CAS extraction can explain this variability, and then discuss the geological implications of this data.

\subsection{Extraction of CAS}

Significant effort has gone into optimizing CAS extraction procedures and this is summarized in detail by Wotte et al. (2012a). They concluded that oxidative leaching steps tend to contaminate CAS by partially oxidizing reduced sulfur phases. Pyrite oxidation would add sulfate to the CAS liberated during dissolution, and cause an increase in sulfate concentration and corresponding change in sulfate isotopic composition (Marenco et al. 2008a; Mazumdar et al. 2008). Point Laframboise has pyrite with sulfur isotopic compositions between -21 and 6\%o (Jones and Fike 2013), so if pyrite oxidation occurred, we would expect it to add ${ }^{34}$ S-depleted sulfate to the analyte solution.

Micrite and bulk-rock specimens contain disseminated pyrite that could not be physically segregated from carbonate components. The results of our pre-cleaning protocol tests (Figure 7) imply the high variability of bulk-rock extractable sulfate cannot be fully explained by procedural contamination of CAS with different sulfur-bearing phases. Pyrite-bearing micrite and bulk-rock samples treated with an oxidative leaching step should be vulnerable to CAS contamination (Wotte et al. 2012a), but the isotopic variation of these samples is still smaller 
411 than that observed between picked carbonate components. Therefore, the Anticosti Island CAS

412 variability is best explained by variation in the relative abundance of carbonate components of 413 the rocks with different CAS compositions.

414 Further, the results of our pyrite dissolution tests (Figure 8) indicate that negligible 415 amounts of pyrite oxidation contributed to the sulfur isolated by our pre-cleaning and CAS 416 extraction protocol. With the exception of one sample, all of the CAS variability in the 417 pyrite/coral mixtures can be explained by the primary range of CAS in the coral without any 418 pyrite (gray field in Figure 8A). This remains true for the coral samples with iron-manganese 419 oxide crusts, which liberate abundant ferric iron and high valent manganese as potential pyrite 420 oxidants during dissolution. The $\delta^{34} \mathrm{~S}$ of the single outlying point (a coral with its ironmanganese crust and $4.7 \mathrm{wt} . \%$ pyrite) is about $1 \%$ lighter than the average sulfur isotopic composition of the coral. However, this point does not fall on the expected vector of increasing

423 CAS concentration and decreasing isotopic composition for pyrite dissolution (black line in

424 Figure 8A). Additionally, samples with higher pyrite content would be expected to experience 425 more pyrite contamination, but there is no relationship between apparent extracted sulfate 426 isotopic composition and pyrite content (Figure 8B). Thus, we conclude that our CAS pre427 cleaning and extraction protocol does not contribute measurable amounts of pyrite-derived 428 sulfate to the primary CAS. In summary, sample pre-cleaning tests (Figure 7) indicate that the CAS variability in our 430 Ordovician-Silurian samples cannot be explained by contamination by non-CAS sulfur bearing 431 phases, and our pyrite dissolution tests (Figure 8) confirm that our extraction protocol leads to 432 negligible oxidation of pyrite. Regardless of the pre-cleaning technique employed, a key strength of this method is the ability to microscopically screen samples for the presence of 
434 possible contaminating phases such as pyrite before dissolution (Figure 5 and Supplemental 435 Figure 2).

\subsection{Brachiopod fibrous calcite CAS preserves seawater composition}

We confirmed that modern brachiopod CAS is close to the isotopic composition of modern seawater sulfate (Figure 6), which is $21.15 \pm 0.15 \%$ (Johnston et al. 2014). The slight

${ }^{34} \mathrm{~S}$-depletion of modern biogenic CAS relative to seawater is comparable to other calcifying organisms that can vary from seawater by up to $2 \%$ (Burdett et al. 1989; Kampschulte et al. 2001; Paris et al. 2014b; Paris et al. 2013).

Brachiopod calcite likely preserves primary geochemical signatures over geologic time scales because it is composed of relatively large and thermodynamically-stable LMC crystals 445 (Popp 1986). In addition, recrystallization, when it occurs, is petrographically obvious (Popp 446 1986). Carefully screened brachiopods offer demonstrably the best proxy archives for many 447 geochemical records, such as seawater carbon, oxygen, and strontium isotopic compositions (Al448 Aasm and Veizer 1982; Cummins et al. 2014; Finnegan et al. 2011; Grossman et al. 1993). Popp 449 (1986) reported the first sulfate-sulfur isotope measurements from 3-5 g of Permo-Carboniferous 450 brachiopods. Kampschulte et al. (2001) extended this Carboniferous brachiopod CAS record, 451 and also compared CAS data from biogenic calcite to that obtained from bulk-rock samples; they 452 observed only about $2 \%$ difference between brachiopods and bulk-rock data. This record of 453 biogenic calcite was expanded to the Phanerozoic-scale by Kampschulte and Strauss (2004) and 454 Wu et al. (2014), but its resolution was limited by the availability of large ( $>1 \mathrm{~g})$, well-preserved 455 brachiopods or samples comprised of multiple brachiopods. 
Indeed, brachiopod calcite from Anticosti Island appears to provide a robust archive for

457 the sulfur isotopic composition of Ordovician-Silurian seawater sulfate. For this study, we

458 microscopically isolated flakes of brachiopod fibrous calcite to avoid small sulfide or iron-

459 bearing inclusions (Figure 5 and Supplemental Figure 2) (i.e., phases that might contaminate

460 CAS). The brachiopod specimens where we isolated enough calcite to also determine the

461 carbonate carbon and oxygen isotopic composition were consistent with chemostratigraphic data

462 published by Jones et al. (2011). The brachiopod calcite specimens show the least CAS sulfur

463 isotopic variability of all observed phases ( $24 \%$ to $26 \%$, except for the outlier in sample 901 -

464 HCS, Figure 9). One outlier specimen (marked by a question mark in Figure 9) was the smallest

465 analyzed (with the least amount of sulfate recovered, less than $10 \mathrm{nmol}$ ), and had poor textural

466 preservation. We analyzed two additional brachiopod specimens from the same hand-sample to

467 confirm that their CAS isotopic compositions fell within the same range as all other brachiopods

468 specimens. From the brachiopod suite, we estimate end-Ordovician and early Silurian seawater

469 sulfate had a sulfur isotopic composition of $24.86 \pm 0.40 \%$ ( 2 s.e., $n=18$, excluding the outlier).

470 The stability of the brachiopods' CAS isotopic composition (Figure 10) implies that seawater

471 sulfate did not significantly vary across the Hirnantian glaciation or Ordovician/Silurian

472 boundary, consistent with the conclusions of Jones and Fike (2013). 


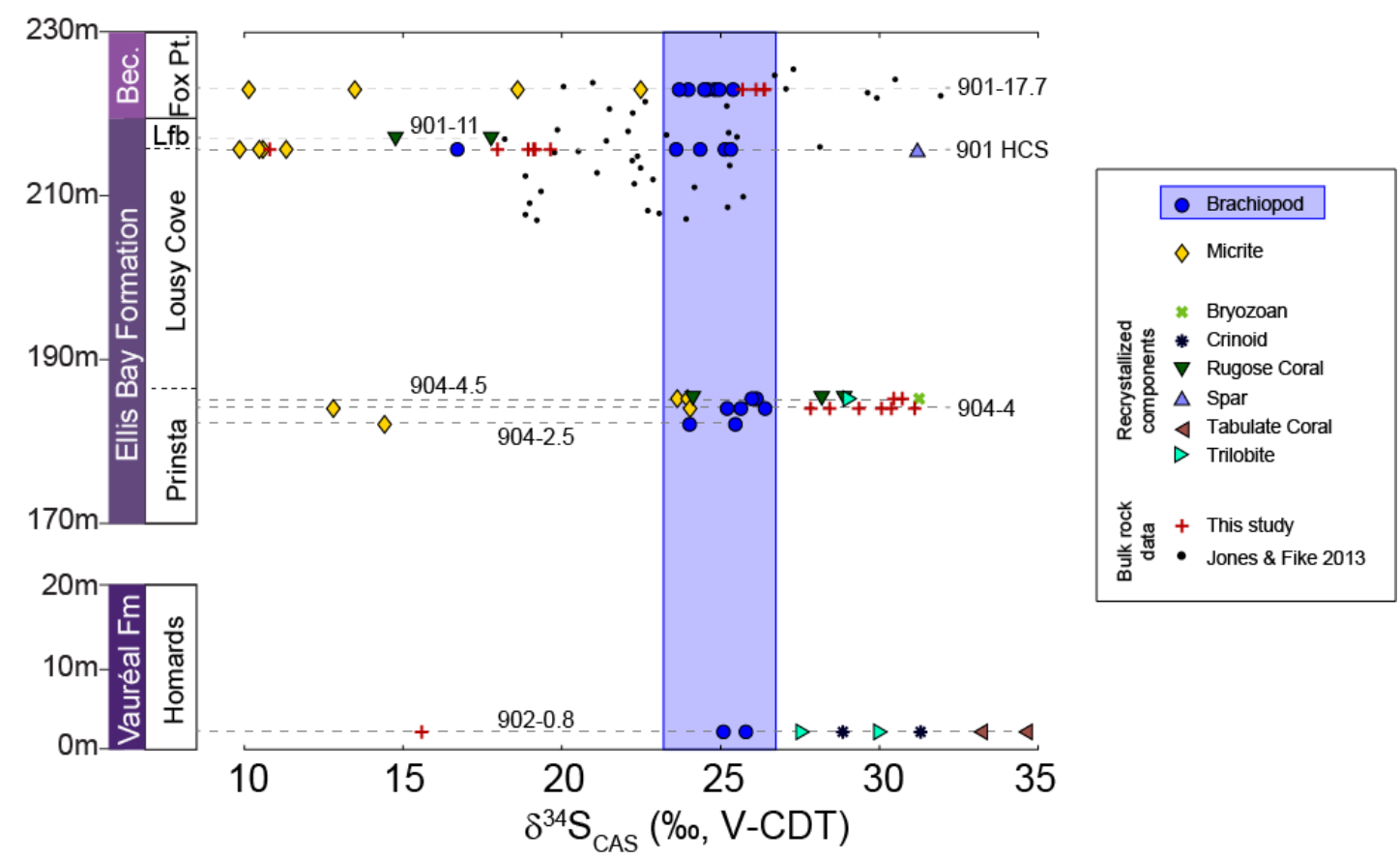

Figure 10: Sulfur isotopic compositions of CAS specimens arranged by stratigraphic height. Colored symbols are data from this study, and small black dots are bulk-rock data from Jones and Fike (2013). The blue field demarcates the range of brachiopod CAS (excluding the small, recrystallized outlier discussed in the text), which does not vary through the succession. Gray dashed lines connect specimens from the same hand-sample. Bec. $=$ Becscie Formation, Lfb. $=$ Laframboise, Pt. $=$ Point.

\subsection{Patterns of CAS isotopic variability in other phases}

There is large $\delta^{34} \mathrm{~S}$ variability in phases other than the well-preserved brachiopods. CAS composition is different between the various components of our samples and is related to petrographic texture. Micrite powders are extremely variable (10\%o to $25 \%$ ) and are consistently isotopically lighter than co-occurring brachiopods (Figure 9, Figure 10). All other components are generally isotopically heavier than brachiopods, and have variable and visible amounts of recrystallization. In aggregate, our texture-specific data can explain the variable composition of homogenized bulk-rock samples (red plusses in Figure 9) as a physical mixture of different sedimentary components. 
Even within each of our analyzed hand-samples there is large heterogeneity in the CAS

491 isotopic composition (Figure 10). For example, we observed a range of as much as $21 \%$ within

492 Sample 901-HCS (Figure 10). In addition, all of the hand-samples are collected from the same

493 distal carbonate ramp facies from the western sector of Anticosti Island, so the variability is not

494 explained by spatial heterogeneity or temporal changes of seawater sulfate. Our observed

495 variability among all measured specimens is larger than the $13 \%$ range of bulk-rock CAS

496 analyzed from the same stratigraphic sections by Jones and Fike (2013) (black dots in Figure 10).

497 Those authors suggested that the bulk-rock CAS variability did not reflect rapid change in the

498 isotopic composition of Ordovician/Silurian seawater sulfate, which they argued remained nearly

499 constant (as confirmed by our brachiopod data) over the duration of the record (less than $1.5 \mathrm{Myr}$

500 as allowed by biostratigraphic constraints).

501 These observations are consistent with the hypothesis that CAS variability on Anticosti

502 Island reflects post-depositional processes. Micrite is commonly targeted for CAS studies and

503 often interpreted to represent lime mud (e.g. Gill et al. $2011 \mathrm{~b}$; Wotte et al. 2012b). We

504 deliberately selected hand-samples with heterogeneous sedimentary components, but high

505 variability is also observed among micrite subsamples within a hand-sample. Micrite can be

506 formed by multiple processes that are not easily distinguishable by rock texture (Flugel and

507 Munnecke 2010). It can be allochthonous (allomicrite) or authigenic (automicrite), precipitate

508 from biological or inorganic processes, form in either seawater or evolved pore fluids, or be the

509 result of physical erosion or biologic boring of larger allochems (Flugel and Munnecke 2010).

510 Micrite must then lithify by addition of carbonate cements and/or recrystallization, processes that

511 can closely associate carbonate components precipitated from different solutions (Lyons et al.

512 2004; Rennie and Turchyn 2014). Our micrite samples are fine-grained carbonate matrix 
material with variable amounts of skeletal fragment allochems (Figure 4). We observed up to $15 \%$ variation between micrite powders milled only a few centimeters apart (yellow diamonds in Figure 10). Like the bulk-rock data, the CAS variability of Anticosti Island micrites is likely a consequence of secondary processes.

\subsection{Diagenetic insights from CAS variability}

By accepting well-preserved brachiopod secondary-layer fibrous calcite CAS as a reliable proxy for seawater sulfate, we can explore the information content of CAS in the other components. Our dataset has two populations around the brachiopods: micrite specimens that are ${ }^{34} \mathrm{~S}$-depleted, and recrystallized specimens that are highly variable and generally ${ }^{34} \mathrm{~S}$-enriched (Figure 9). Processes likely to diagenetically alter sulfate isotopic composition from seawater are sulfide oxidation and MSR.

Previous workers have examined the potential for non-seawater sulfate sources in CAS.

Two important studies suggested that the isotopic composition of CAS can be resistant to diagenetic alteration. Lyons et al. (2004) showed that the isotopic composition of bulk-sediment CAS remained unchanged in a carbonate mud sediment core with both carbonate precipitation and sulfate reduction. Secondly, Gill et al. (2008) showed that CAS $\delta^{34} \mathrm{~S}$ in a recent aragonitic head coral remains unchanged by aragonite neomorphism during meteoric diagenesis. However, those authors noted that these settings lack the leverage to substantially alter CAS. In the first case, diagenetically-precipitated carbonate represented a small portion of the total sediment mass relative to primary carbonate. In the second case, meteoric fluids have very little sulfate. Contrastingly, other researchers have identified diagenetic alteration of CAS. Rennie and Turchyn (2014) demonstrated that CAS in late Cenozoic nanofossil ooze bulk sediment may be 
${ }^{34} \mathrm{~S}$-enriched relative to seawater if carbonate cementation is slower than enrichment of pore fluid sulfate by MSR, but only by up to about $4 \%$ under those relative sedimentary fluxes. On longer timescales, Marenco et al. (2008b) argued that dolomitization incorporates ${ }^{34}$ S-depleted sulfateby up to about 10\%o- into CAS. Loyd et al. (2012a) looked specifically at diagenetic carbonate concretions forming from pore fluids where sulfate reduction was prominent, and observed large enrichment (up to $15 \%$ ) relative to seawater. However, these studies have not observed the range of values (24.7\%) measured in the limestones preserved on Anticosti Island, which includes both large ${ }^{34} \mathrm{~S}$-enrichments and depletions relative to the inferred isotopic composition of seawater.

Micrite powders from Anticosti Island lie on an array of increasing CAS concentration and decreasing isotopic composition (yellow ellipse in Figure 9). Such a trend is predicted by oxidation of pyrite during CAS extraction (Marenco et al. 2008a; Mazumdar et al. 2008), but as discussed above from experimental results, we think this type of contamination was negligible in our procedure. Instead, natural sulfide oxidation sometime in the rocks' histories, followed by precipitation of more carbonate to incorporate the CAS, may explain the diagenetic array. This could have occurred before lithification, and pore fluid aqueous sulfide oxidation could have been microbially mediated. Later stabilization, cementation and lithification of the micrite could have incorporated variable amounts of this recycled sulfur.

Alternatively, fluids carrying ${ }^{34} \mathrm{~S}$-depleted sulfate could have migrated from a separate locus of pyrite oxidation to the lithifying or recrystallizing micrites, and effected other geochemical changes (e.g. dolomitizing fluids in Marenco et al. 2008b). Of all of the micrite samples we analyzed, the lightest CAS sulfur isotopic composition came from Sample 901-HCS, which is the only dolomite-containing wackestone in our sample suite (Figure 10). Previously- 
collected clumped isotope data from Anticosti Island provide further evidence that micrite diagenesis proceeded in an open system with respect to fluid-rock interactions (Finnegan et al. 2011).

A third option is that sulfide oxidation could have occurred during modern surficial weathering or sea level lows younger than the rock, when corrosive meteoric fluids could mobilize sulfur derived from pyrite. Weathering of pyrite would produce insoluble iron oxides (such as goethite or hematite) and aqueous sulfate, and the latter could be incorporated into recrystallizing carbonate minerals. Some micrite samples showed petrographic evidence for iron oxides. Also, rock magnetic data shows evidence for a low-temperature $\left(<100^{\circ} \mathrm{C}\right)$ thermallydecomposed component oriented parallel to the modern magnetic field (Seguin and Petryk 1986). Seguin and Petryk (1986) report demagnetizing about $200 \mathrm{~mA} / \mathrm{m}$ of this component, which is probably goethite. Assuming it is all goethite (density of $\sim 4.3 \mathrm{~g} / \mathrm{cm}^{3}$ and saturation magnetism of $\left.\sim 2 \mathrm{emu} / \mathrm{cm}^{3}\right)$, then the rocks $\left(\sim 2.7 \mathrm{~g} / \mathrm{cm}^{3}\right)$ have about 200 ppmv goethite. For our $10 \mathrm{mg}$ rock specimens, this corresponds to about $35 \mathrm{nmol}$ of iron. If all of the iron is from weathered pyrite in a closed system, then potentially $70 \mathrm{nmol}$ of weathered and oxidized sulfide could have contaminated the CAS. Most micrite specimens were about $70 \%$ carbonate, corresponding to potentially $\sim 1000 \mathrm{ppm}$ "weathered" sulfate contamination. Thus, micrites from hand-sample 901-HCS, for example, could include up to about $65 \%$ weathered sulfide incorporated as CAS. However, meteoric dissolution of pyrite would also be corrosive to carbonate, and not conducive to incorporation into micrite CAS. Thus, we hypothesize that Anticosti Island micrite CAS records active microbial sulfide oxidization in the OrdovicianSilurian-age shelf sediments. 
The CAS composition of calcite spar and recrystallized coral, trilobite, crinoid, and

bryozoan fossils varies widely (field enclosed by dashed line in Figure 9). Most are ${ }^{34} \mathrm{~S}$-enriched with respect to the brachiopods, and likely incorporated ${ }^{34} \mathrm{~S}$-enriched sulfate that was the residual of MSR. The most recrystallized fossil was a tabulate coral (Sample 902-0.8, Supplemental Figure 1), which also had the heaviest CAS composition (33 to 34\%o). These recrystallized fossils were likely precipitated as high-magnesium calcite and susceptible to stabilization to LMC (Wilkinson 1979). Specimens from Anticosti Island recrystallized late in the burial diagenesis process at clumped-isotope temperatures over $50^{\circ} \mathrm{C}$, coinciding with enrichments of iron and manganese and depletion of strontium indicative of meteoric groundwater (Finnegan et al. 2011). Explaining the ${ }^{34} \mathrm{~S}$-enriched CAS in recrystallized phases requires an aquifer where water is significantly ${ }^{34} \mathrm{~S}$-enriched by MSR and sulfate-rich enough for this modified groundwater sulfate to be incorporated into CAS. Dogramaci et al. (2001) describe a potential modern analog in the western Murray Basin, Australia where sulfate in a deep, confined aquifer has an isotopic composition between $20 \%$ and $60 \%$ and is from a mixture of marine and freshwater. The highly heterogeneous CAS in recrystallized specimens from Anticosti Island may record calcite stabilization in a similar heterogeneous and sulfate-bearing aquifer.

\section{Conclusions}

With a new MC-ICP-MS analytical technique for sulfate, we demonstrated that the CAS of common petrographic textures can be highly heterogeneous on small spatial scales in wellpreserved marine limestones from late Ordovician and early Silurian-age strata on Anticosti Island. This heterogeneity does not reflect spatial or temporal variability in aqueous marine sulfate. Instead, it records part of the diagenetic history of the samples. Because our analytical 
technique can be applied to small samples, it allows for the careful selection of samples wellsuited as archives of seawater sulfate. Well-preserved brachiopod fibrous calcite could be successfully isolated from other CAS-bearing phases and pyrite, and provides a reliable archive.

Our Anticosti Island brachiopod data provide a record of marine sulfate maintaining a $\delta^{34} \mathrm{~S}$ composition of $24.86 \pm 0.40 \%$ (2s.e.) through the Ordovician-Silurian boundary interval. This confirms that despite substantial changes in biogeochemical cycling and climate through the Hirnantian, no excursion occurred in the isotopic composition of seawater sulfate, consistent with the conclusions of Jones and Fike (2013). Given the constancy of marine sulfate's isotopic composition, CAS sulfur isotopes from micrite and other components demonstrate the importance of secondary processes and vary by nearly the total range of secular variation observed over the Phanerozoic Eon. On Anticosti Island, the CAS in micrite is ${ }^{34} \mathrm{~S}$-depleted relative to contemporaneous seawater, and may be explained by sulfide oxidation in pore fluids during early diagenesis, or incorporation of ${ }^{34} \mathrm{~S}$-depleted sulfate-rich dolomitizing fluids. The CAS in components recrystallized during burial diagenesis is characterized by $\delta^{34} \mathrm{~S}$ values higher than contemporaneous seawater, and requires active sulfate reduction in Anticosti Island groundwater.

More generally, our data suggest that scatter in Phanerozoic bulk-rock CAS records (e.g. those shown in Figure 1) does not unambiguously record primary seawater sulfate chemistry, and could reflect later incorporation of sulfate modified by early diagenetic and recrystallization processes. Analyzing well-preserved specimens allows for a more precise and accurate record of seawater sulfate than numerically smoothing noisy datasets — there is no guarantee that variation in a dataset is symmetrical about the value of seawater during the time of deposition. In addition, once primary changes in seawater sulfate composition are better constrained, the 
remaining variation in CAS records can provide additional information about secondary local

628 biogeochemical processes during lithification and burial. Large $\delta^{34} \mathrm{~S}$ variability in coexisting

629 carbonate components - including in calcimudstone and wackestone samples commonly called

630 micrite and analyzed in CAS records of all ages - may be indicative of unique diagenetic

631 regimes. Fluxes associated with pore fluid sulfide oxidation and groundwater sulfate reduction

632 are poorly constrained in modern sediments and aquifers, but may be important biogeochemical

633 processes in Earth's history. Overall, new approaches analyzing CAS in smaller, carefully

634 characterized samples will improve the accuracy and precision of the marine sulfate record.

636 Acknowledgements

Funding for this work was provided by the American Chemical Society Petroleum

638 Research Fund New Directions grant \#53994-ND2, NSF Division of Earth Sciences award EAR-

639 1349858, and the Agouron Institute. We thank David Jones and Benjamin Gill for thoughtful

640 reviews. We thank David Fike and Seth Finnegan for helpful input and field context for the

641 Anticosti Island specimens. We thank Renata Cummins for instruction on how to prepare

642 brachiopod secondary-layer fibrous calcite, and Lindsey Hedges, Fenfang Wu, and Nathan

643 Dalleska for analytical support. We thank Joe Kirschvink for help interpreting rock magnetic

644 data. Thank you to Kristin Bergmann for providing the T. transversa specimen, and Nivedita

645 Thiagarajan for help preparing deep-sea coral samples. Ion chromatography was done at the

646 Caltech Environmental Analysis Center. 


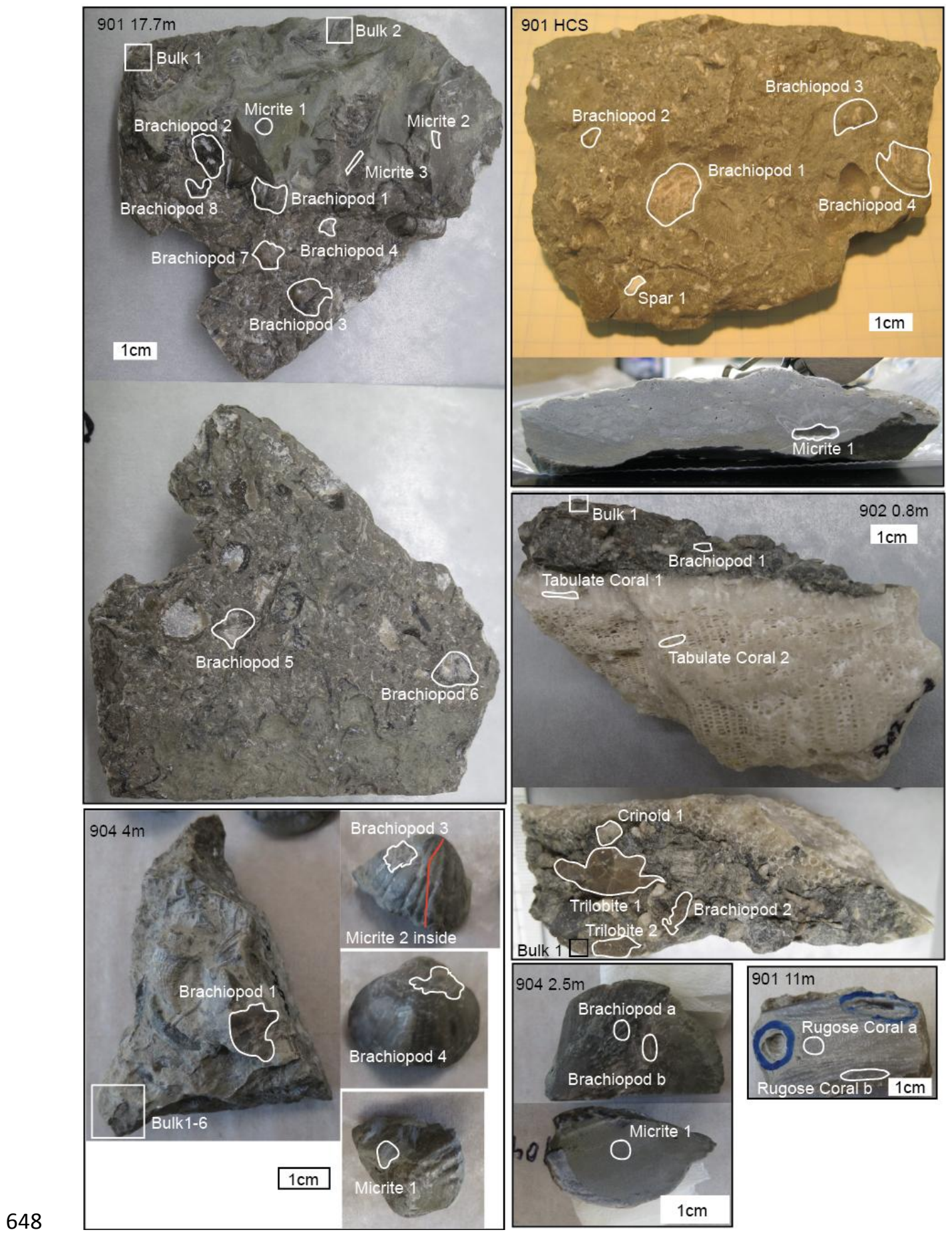

649 Supplemental Figure 1: Analyzed specimens from the six remaining hand-samples not shown in 650 the main text. 

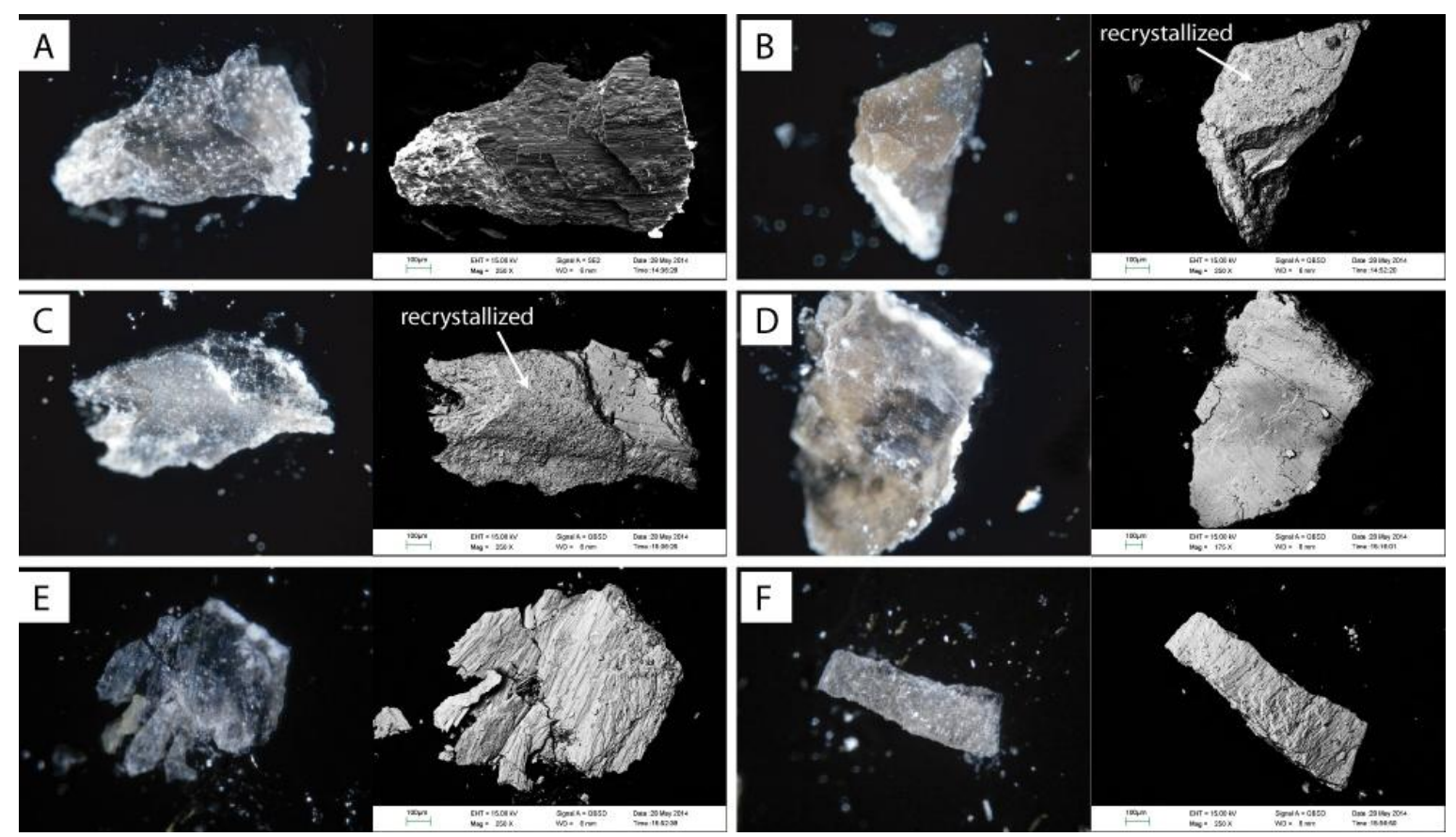

Supplemental Figure 2: Binocular microscope (left) and electron microscope backscatter intensity (right) images of more representative flakes picked from brachiopod specimens to illustrate how flakes were included or excluded in CAS analyses. (A) Sample 904-4.5m, Brachiopod 1 still shows fibrous calcite lineation and is optically transparent; flakes like this would have been dissolved for analysis. (B) A poorly-preserved flake from Sample 904-4.5m, Brachiopod 2 has lost its fibrous calcite texture and incorporated contaminants that caused yellowing during recrystallization. Flakes like this would normally be removed from specimens before dissolution. However, this specimen was prohibitively small and included recrystallized flakes. (C) A flake from Sample 904-4.5m, Brachiopod 3 with both well-preserved and recrystallized fibrous calcite. A flake like this would have been further broken with the point of a dental pick so that only the optically transparent portions would be kept for analysis. (D) A flake from Sample 904-4.5m, Brachiopod 4 still maintains the fibrous calcite lineations and is generally transparent, but has some discoloration associated with recrystallization. Flakes like this were kept and analyzed in this specimen. (E) A well-preserved flake from Sample 904-4m, Brachiopod 3. (F) A well-preserved flake from Sample 904-4m, Brachiopod 4. 

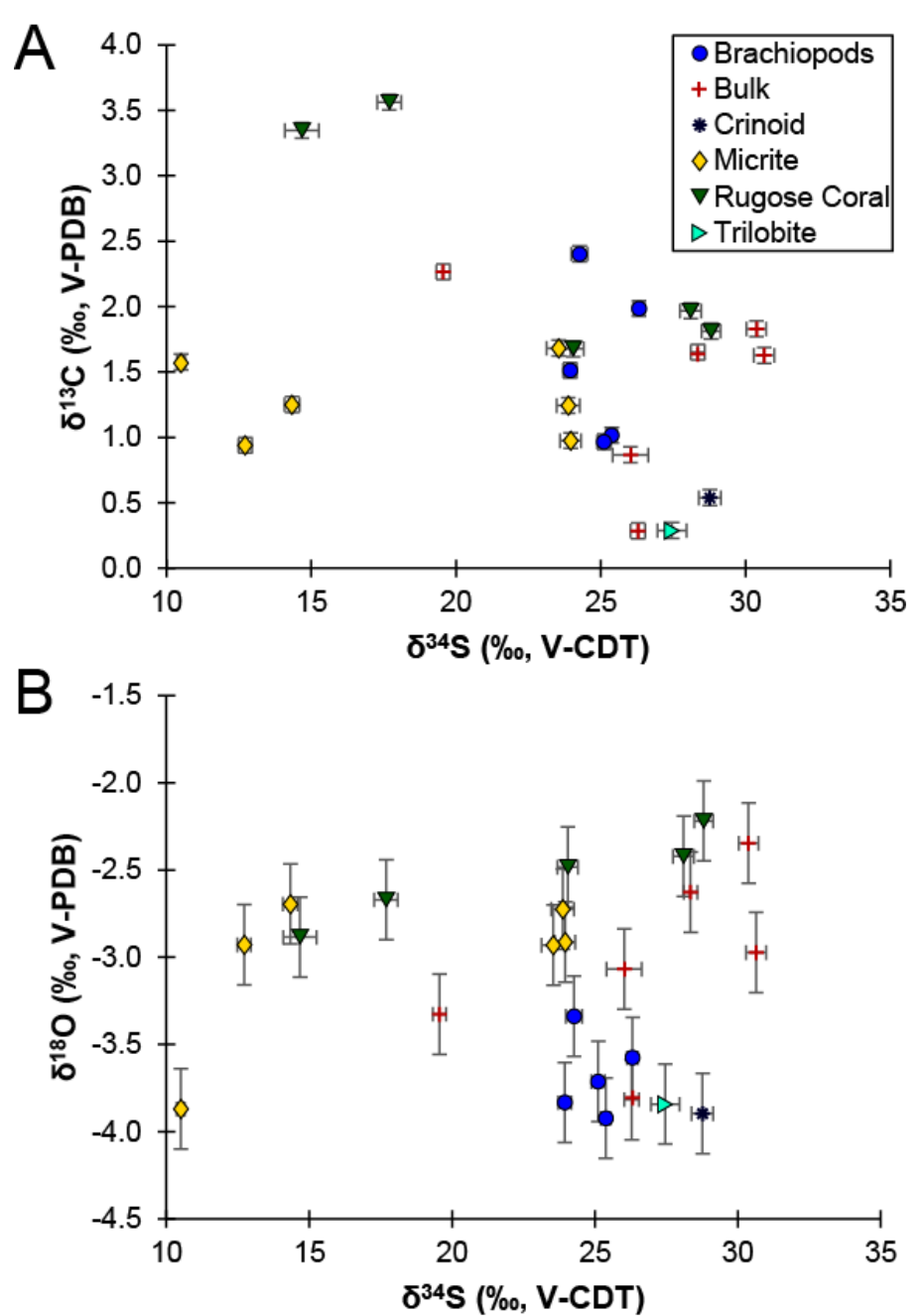

Supplemental Figure 3: Carbonate (A) carbon and (B) oxygen isotopic compositions of 670 remaining powders and flakes after CAS analysis. 
671

672

673

674

675

676

677

678

679

680

681

682

683

684

685

686

687

688

689

690

691

692

693

694

695

696

697

698

699

700

701

702

703

704

705

706

707

708

709

710

711

712

713

714

715

716

717

718

\section{References}

Al-Aasm, I.S. \& Veizer, J. 1982. Chemical stabilization of low-Mg calcite; an example of brachiopods. Journal of Sedimentary Research, 52, 1101-1109, doi: 10.1306/212f80e4-2b24-11d78648000102c1865d.

Bottrell, S.H. \& Newton, R.J. 2006. Reconstruction of changes in global sulfur cycling from marine sulfate isotopes. Earth-Science Reviews, 75, 59-83, doi: http://dx.doi.org/10.1016/j.earscirev.2005.10.004. Burdett, J.W., Arthur, M.A. \& Richardson, M. 1989. A Neogene seawater sulfur isotope age curve from calcareous pelagic microfossils. Earth and Planetary Science Letters, 94, 189-198, doi: 10.1016/0012821x(89)90138-6.

Came, R.E., Eiler, J.M., Veizer, J., Azmy, K., Brand, U. \& Weidman, C.R. 2007. Coupling of surface temperatures and atmospheric CO2 concentrations during the Palaeozoic era. Nature, 449, 198-201, doi: http://www.nature.com/nature/journal/v449/n7159/suppinfo/nature06085_S1.html.

Copper, P., Jin, J. \& Desrochers, A. 2013. The Ordovician-Silurian boundary (late Katian-Hirnantian) of western Anticosti Island: revised stratigraphy and benthic megafaunal correlations. Stratigraphy, 10, 213-227.

Cummins, R.C., Finnegan, S., Fike, D.A., Eiler, J.M. \& Fischer, W.W. 2014. Carbonate clumped isotope constraints on Silurian ocean temperature and seawater $\delta 180$. Geochimica et Cosmochimica Acta, 140, 241-258, doi: http://dx.doi.org/10.1016/j.gca.2014.05.024.

Desrochers, A., Farley, C., Achab, A., Asselin, E. \& Riva, J.F. 2010. A far-field record of the end Ordovician glaciation: The Ellis Bay Formation, Anticosti Island, Eastern Canada. Palaeogeography,

Palaeoclimatology, Palaeoecology, 296, 248-263, doi: http://dx.doi.org/10.1016/j.palaeo.2010.02.017. Desrochers, A. \& Gauthier, É.L. 2009. Carte géologique de l'île d'Anticosti (1/250 000), DV 2009-03. Dogramaci, S.S., Herczeg, A.L., Schiff, S.L. \& Bone, Y. 2001. Controls on $\delta 34 S$ and $\delta 180$ of dissolved sulfate in aquifers of the Murray Basin, Australia and their use as indicators of flow processes. Applied Geochemistry, 16, 475-488, doi: http://dx.doi.org/10.1016/S0883-2927(00)00052-4.

Finnegan, S., Bergmann, K., Eiler, J.M., Jones, D.S., Fike, D.A., Eisenman, I., Hughes, N.C., Tripati, A.K. \& Fischer, W.W. 2011. The Magnitude and Duration of Late Ordovician-Early Silurian Glaciation. Science, 331, 903-906.

Finnegan, S., Heim, N.A., Peters, S.E. \& Fischer, W.W. 2012. Climate change and the selective signature of the Late Ordovician mass extinction. Proceedings of the National Academy of Sciences, 109, 68296834.

Flugel, E. \& Munnecke, A. 2010. Microfacies of carbonate rocks: analysis, interpretation and application. Springer-Verlag.

Garrels, R.M. \& Lerman, A. 1984. Coupling of the sedimentary sulfur and carbon cycles; an improved model. American Journal of Science, 284, 989-1007, doi: 10.2475/ajs.284.9.989.

Gill, B.C., Lyons, T.W. \& Frank, T.D. 2008. Behavior of carbonate-associated sulfate during meteoric diagenesis and implications for the sulfur isotope paleoproxy. Geochimica et Cosmochimica Acta, 72, 4699-4711, doi: 10.1016/j.gca.2008.07.001.

Gill, B.C., Lyons, T.W. \& Jenkyns, H.C. 2011a. A global perturbation to the sulfur cycle during the Toarcian Oceanic Anoxic Event. Earth and Planetary Science Letters, 312, 484-496, doi:

10.1016/j.epsl.2011.10.030.

Gill, B.C., Lyons, T.W. \& Saltzman, M.R. 2007. Parallel, high-resolution carbon and sulfur isotope records of the evolving Paleozoic marine sulfur reservoir. Palaeogeography, Palaeoclimatology, Palaeoecology, 256, 156-173, doi: 10.1016/j.palaeo.2007.02.030.

Gill, B.C., Lyons, T.W., Young, S.A., Kump, L.R., Knoll, A.H. \& Saltzman, M.R. 2011b. Geochemical evidence for widespread euxinia in the Later Cambrian ocean. Nature, 469, 80-83, doi:

http://www.nature.com/nature/journal/v469/n7328/abs/nature09700.html\#supplementaryinformation. 
Goldberg, T., Poulton, S.W. \& Strauss, H. 2005. Sulphur and oxygen isotope signatures of late Neoproterozoic to early Cambrian sulphate, Yangtze Platform, China: Diagenetic constraints and seawater evolution. Precambrian Research, 137, 223-241, doi: http://dx.doi.org/10.1016/j.precamres.2005.03.003.

Gorjan, P., Kaiho, K., Fike, D.A. \& Xu, C. 2012. Carbon- and sulfur-isotope geochemistry of the Hirnantian (Late Ordovician) Wangjiawan (Riverside) section, South China: Global correlation and environmental event interpretation. Palaeogeography, Palaeoclimatology, Palaeoecology, 337-338, 14-22, doi: http://dx.doi.org/10.1016/j.palaeo.2012.03.021. Grossman, E.L., Mii, H.-S. \& Yancey, T.E. 1993. Stable isotopes in Late Pennsylvanian brachiopods from the United States: Implications for Carboniferous paleoceanography. Geological Society of America Bulletin, 105, 1284-1296, doi: 10.1130/0016-7606(1993)105<1284:siilpb>2.3.co;2.

Hammarlund, E.U., Dahl, T.W., Harper, D.A.T., Bond, D.P.G., Nielsen, A.T., Bjerrum, C.J., Schovsbo, N.H., Schönlaub, H.P., Zalasiewicz, J.A. \& Canfield, D.E. 2012. A sulfidic driver for the end-Ordovician mass extinction. Earth and Planetary Science Letters, 331-332, 128-139, doi: http://dx.doi.org/10.1016/j.epsl.2012.02.024.

Hurtgen, M.T., Pruss, S.B. \& Knoll, A.H. 2009. Evaluating the relationship between the carbon and sulfur cycles in the later Cambrian ocean: An example from the Port au Port Group, western Newfoundland, Canada. Earth and Planetary Science Letters, 281, 288-297, doi: http://dx.doi.org/10.1016/j.epsl.2009.02.033. Johnston, D.T., Gill, B.C., Masterson, A., Beirne, E., Casciotti, K.L., Knapp, A.N. \& Berelson, W. 2014. Placing an upper limit on cryptic marine sulphur cycling. Nature, advance online publication, doi: 10.1038/nature13698.

Jones, D.S. \& Fike, D.A. 2013. Dynamic sulfur and carbon cycling through the end-Ordovician extinction revealed by paired sulfate-pyrite $\delta^{34}$ S. Earth and Planetary Science Letters, 363, 144-155.

Jones, D.S., Fike, D.A., Finnegan, S., Fischer, W.W., Schrag, D.P. \& McCay, D. 2011. Terminal Ordovician carbon isotope stratigraphy and glacioeustatic sea-level change across Anticosti Island (Québec, Canada). Geological Society of America Bulletin, 123, 1645-1664, doi: 10.1130/b30323.1. Kah, L.C., Lyons, T.W. \& Frank, T.D. 2004. Low marine sulphate and protracted oxygenation of the Proterozoic biosphere. Nature, 431, 834-838, doi: http://www.nature.com/nature/journal/v431/n7010/suppinfo/nature02974_S1.html. Kampschulte, A., Bruckschen, P. \& Strauss, H. 2001. The sulphur isotopic composition of trace sulphates in Carboniferous brachiopods: implications for coeval seawater, correlation with other geochemical cycles and isotope stratigraphy. Chemical Geology, 175, 149-173, doi: 10.1016/s0009-2541(00)00367-3. Kampschulte, A. \& Strauss, H. 2004. The sulfur isotopic evolution of Phanerozoic seawater based on the analysis of structurally substituted sulfate in carbonates. Chemical Geology, 204, 255-286, doi: 10.1016/j.chemgeo.2003.11.013.

Loyd, S.J., Berelson, W.M., Lyons, T.W., Hammond, D.E. \& Corsetti, F.A. 2012a. Constraining pathways of microbial mediation for carbonate concretions of the Miocene Monterey Formation using carbonateassociated sulfate. Geochimica et Cosmochimica Acta, 78, 77-98, doi: http://dx.doi.org/10.1016/j.gca.2011.11.028. Loyd, S.J., Marenco, P.J., Hagadorn, J.W., Lyons, T.W., Kaufman, A.J., Sour-Tovar, F. \& Corsetti, F.A. 2012b. Sustained low marine sulfate concentrations from the Neoproterozoic to the Cambrian: Insights from carbonates of northwestern Mexico and eastern California. Earth and Planetary Science Letters, 339-340, 79-94, doi: http://dx.doi.org/10.1016/j.epsl.2012.05.032.

Lyons, T.W., Walter, L.M., Gellatly, A.M., Martini, A.M. \& Blake, R.E. 2004. Sites of anomalous organic remineralization in the carbonate sediments of South Florida, USA: The sulfur cycle and carbonateassociated sulfate. SPECIAL PAPERS-GEOLOGICAL SOCIETY OF AMERICA, 161-176. 
Marenco, P.J., Corsetti, F.A., Hammond, D.E., Kaufman, A.J. \& Bottjer, D.J. 2008a. Oxidation of pyrite during extraction of carbonate associated sulfate. Chemical Geology, 247, 124-132.

Marenco, P.J., Corsetti, F.A., Kaufman, A.J. \& Bottjer, D.J. 2008b. Environmental and diagenetic variations in carbonate associated sulfate: An investigation of CAS in the Lower Triassic of the western USA. Geochimica et Cosmochimica Acta, 72, 1570-1582.

Mazumdar, A., Goldberg, T. \& Strauss, H. 2008. Abiotic oxidation of pyrite by Fe(III) in acidic media and its implications for sulfur isotope measurements of lattice-bound sulfate in sediments. Chemical Geology, 253, 30-37, doi: http://dx.doi.org/10.1016/j.chemgeo.2008.03.014.

Newton, R.J., Reeves, E.P., Kafousia, N., Wignall, P.B., Bottrell, S.H. \& Sha, J. 2011. Low marine sulfate concentrations and the isolation of the European epicontinental sea during the Early Jurassic. Geology, 39, 7-10, doi: 10.1130/g31326.1.

Paris, G., Adkins, J.F., Sessions, A.L., Webb, S.M. \& Fischer, W.W. 2014a. Neoarchean carbonateassociated sulfate records positive $\Delta 33 S$ anomalies. Science, 346, 739-741, doi:

10.1126/science.1258211.

Paris, G., Fehrenbacher, J.S., Sessions, A.L., Spero, H.J. \& Adkins, J.F. 2014b. Experimental determination of carbonate-associated sulfate $\delta 34 \mathrm{~S}$ in planktonic foraminifera shells. Geochemistry, Geophysics, Geosystems, 15, 1452-1461, doi: 10.1002/2014GC005295.

Paris, G., Sessions, A.L., Subhas, A.V. \& Adkins, J.F. 2013. MC-ICP-MS measurement of $\delta 34 S$ and $\Delta 33 S$ in small amounts of dissolved sulfate. Chemical Geology, 345, 50-61, doi:

http://dx.doi.org/10.1016/j.chemgeo.2013.02.022.

Popp, B. 1986. The record of carbon, oxygen, sulfur, and strontium isotopes and trace elements in late Paleozoic brachiopods [Ph. D. thesis]: Urbana. PhD.

Rennie, V.C.F. \& Turchyn, A.V. 2014. The preservation of and in carbonate-associated sulfate during marine diagenesis: A 25 Myr test case using marine sediments. Earth and Planetary Science Letters, 395, 13-23, doi: http://dx.doi.org/10.1016/j.epsl.2014.03.025.

Rohrssen, M., Love, G.D., Fischer, W., Finnegan, S. \& Fike, D.A. 2013. Lipid biomarkers record fundamental changes in the microbial community structure of tropical seas during the Late Ordovician Hirnantian glaciation. Geology, 41, 127-130, doi: 10.1130/g33671.1.

Saltzman, M.R. \& Young, S.A. 2005. Long-lived glaciation in the Late Ordovician? Isotopic and sequencestratigraphic evidence from western Laurentia. Geology, 33, 109-112.

Seguin, M.K. \& Petryk, A.A. 1986. Paleomagnetic study of the Late Ordovician-Early Silurian platform sequence of Anticosti Island, Quebec. Canadian Journal of Earth Sciences, 23, 1880-1890, doi: 10.1139/e86-176.

Song, H., Tong, J., Algeo, T.J., Song, H., Qiu, H., Zhu, Y., Tian, L., Bates, S., Lyons, T.W., Luo, G. \& Kump, L.R. 2014. Early Triassic seawater sulfate drawdown. Geochimica et Cosmochimica Acta, 128, 95-113, doi: http://dx.doi.org/10.1016/j.gca.2013.12.009.

Thompson, C.K. \& Kah, L.C. 2012. Sulfur isotope evidence for widespread euxinia and a fluctuating oxycline in Early to Middle Ordovician greenhouse oceans. Palaeogeography, Palaeoclimatology, Palaeoecology, 313-314, 189-214, doi: http://dx.doi.org/10.1016/j.palaeo.2011.10.020. Wilkinson, B.H. 1979. Biomineralization, paleoceanography, and the evolution of calcareous marine organisms. Geology, 7, 524-527, doi: 10.1130/0091-7613(1979)7<524:bpateo>2.0.co;2.

Wotte, T., Shields-Zhou, G.A. \& Strauss, H. 2012a. Carbonate-associated sulfate: Experimental comparisons of common extraction methods and recommendations toward a standard analytical protocol. Chemical Geology, 326-327, 132-144, doi: http://dx.doi.org/10.1016/j.chemgeo.2012.07.020. Wotte, T., Strauss, H., Fugmann, A. \& Garbe-Schönberg, D. 2012b. Paired $\delta^{34} S$ data from carbonateassociated sulfate and chromium-reducible sulfur across the traditional Lower-Middle Cambrian boundary of W-Gondwana. Geochimica et Cosmochimica Acta, 85, 228-253, doi: http://dx.doi.org/10.1016/j.gca.2012.02.013. 
814 Wu, N., Farquhar, J. \& Strauss, H. 2014. $834 \mathrm{~S}$ and $\Delta 33 \mathrm{~S}$ records of Paleozoic seawater sulfate based on 815 the analysis of carbonate associated sulfate. Earth and Planetary Science Letters, 399, 44-51, doi:

816 http://dx.doi.org/10.1016/j.epsl.2014.05.004.

817 Yan, D., Chen, D., Wang, Q., Wang, J. \& Wang, Z. 2009. Carbon and sulfur isotopic anomalies across the 818 Ordovician-Silurian boundary on the Yangtze Platform, South China. Palaeogeography,

819 Palaeoclimatology, Palaeoecology, 274, 32-39, doi: 10.1016/j.palaeo.2008.12.016.

820 Zhang, T., Shen, Y., Zhan, R., Shen, S. \& Chen, X. 2009. Large perturbations of the carbon and sulfur cycle 821 associated with the Late Ordovician mass extinction in South China. Geology, 37, 299-302, doi:

822 10.1130/g25477a.1. 

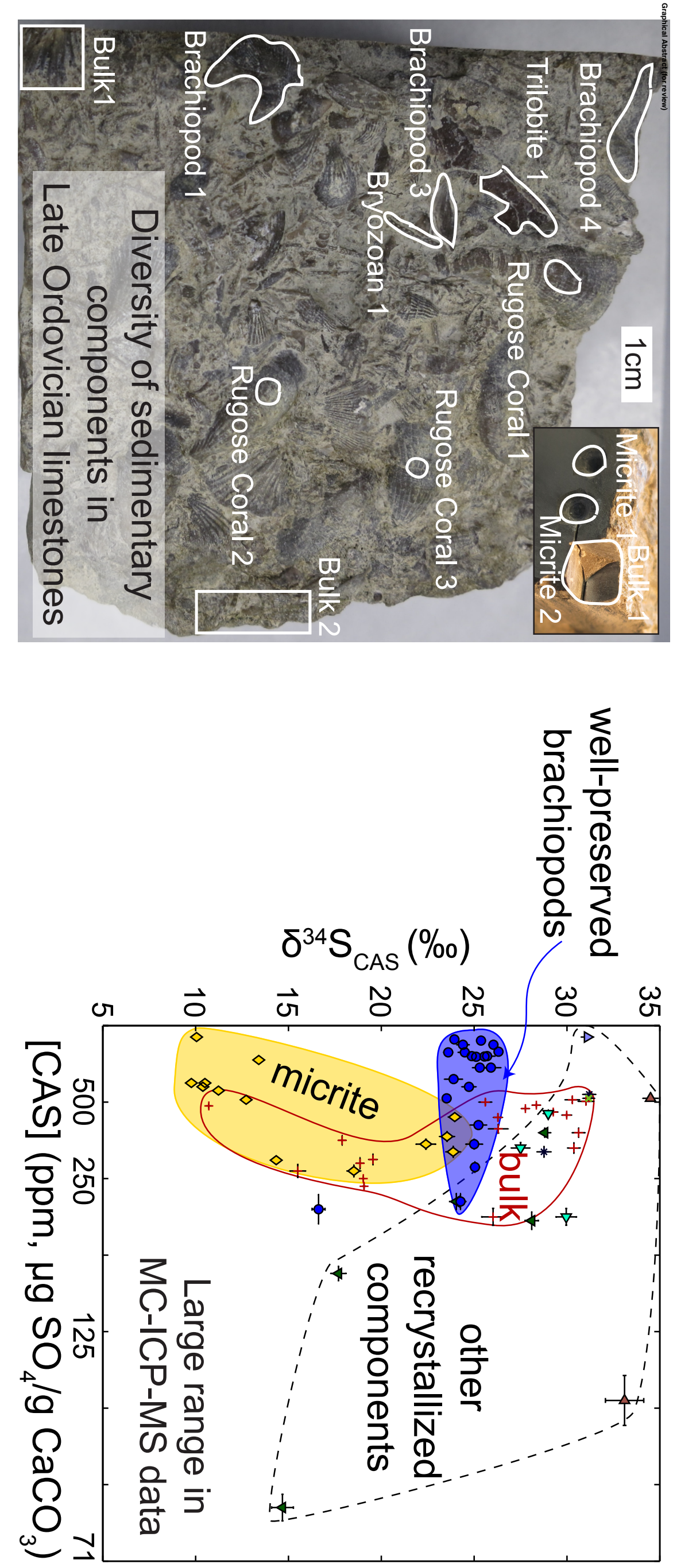


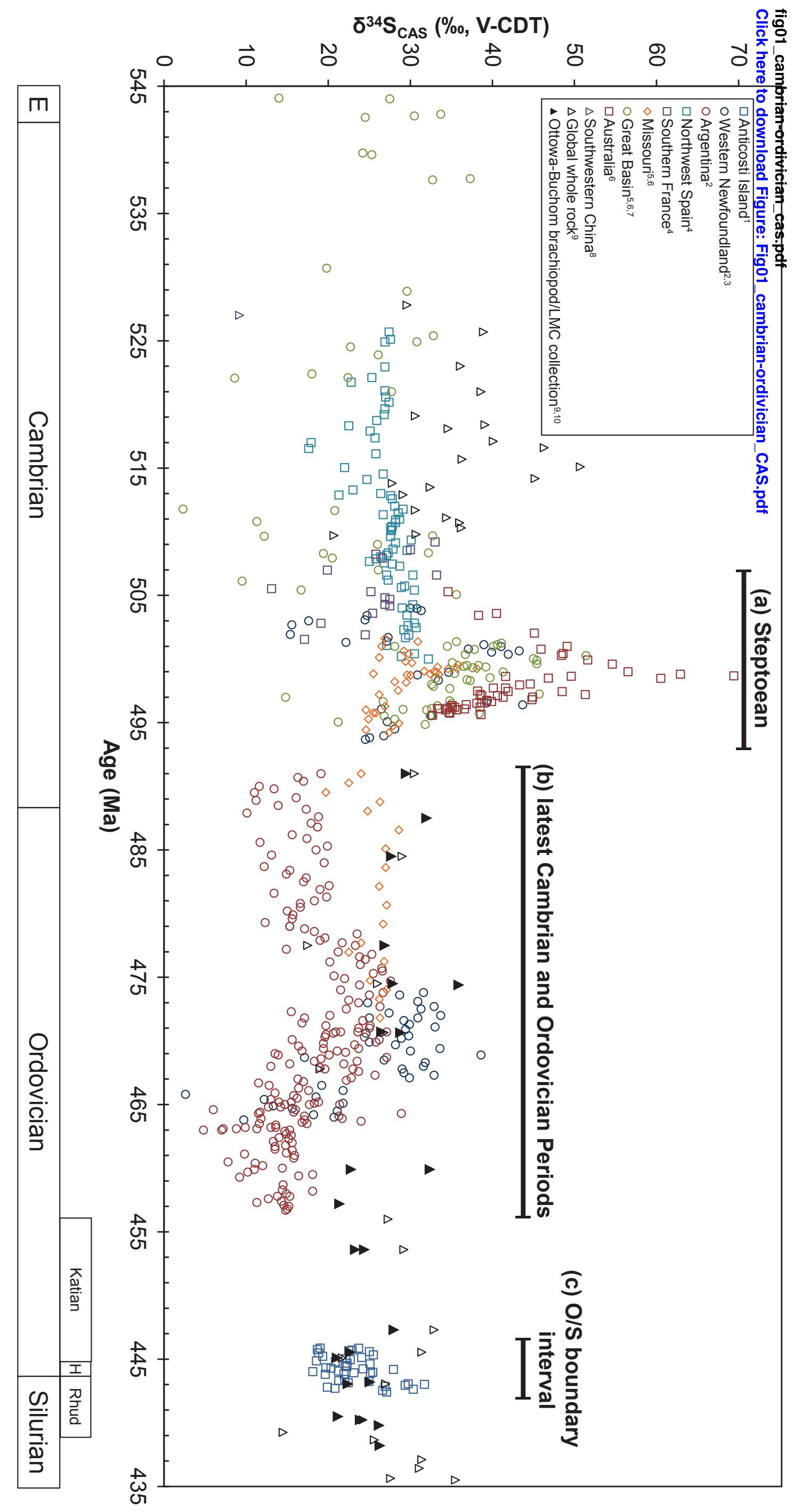




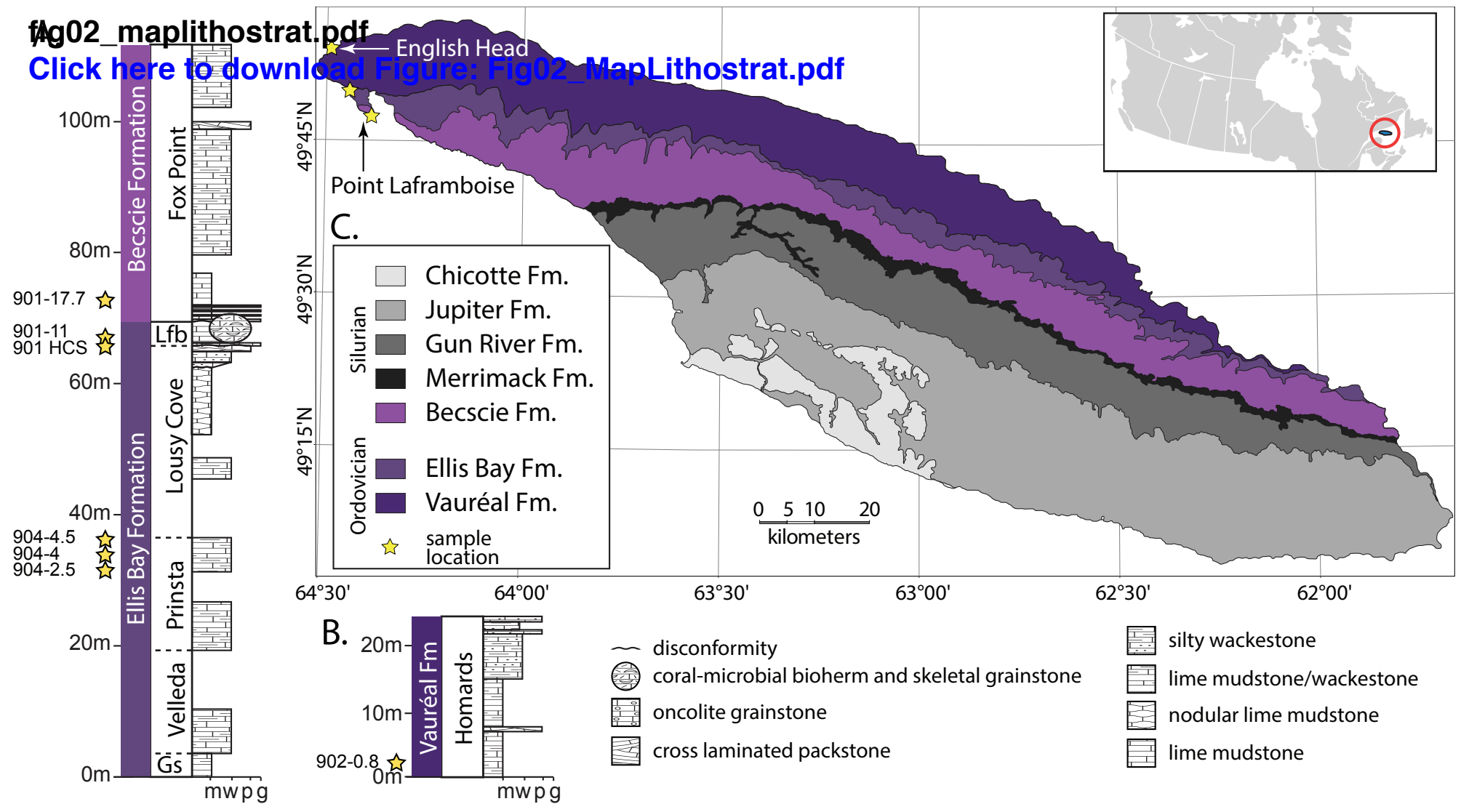


fig03 specimens_main.pdf

Clic Fere to download Figure: FPo03.5specimens_main.pdf

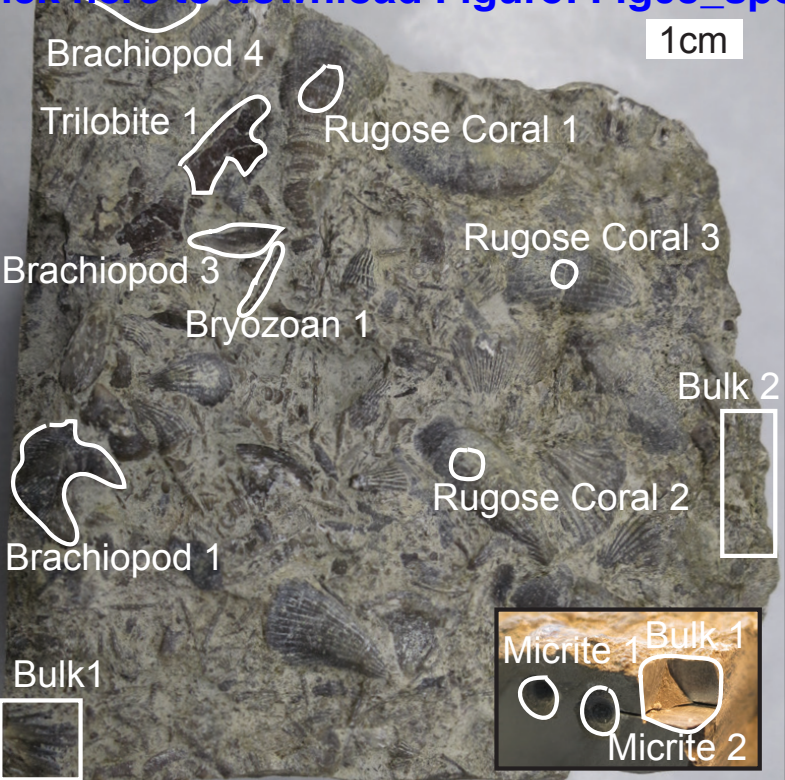


fig04_thick_sections.pdf

Click here to download Figure: Fig04_thick_sections.pdf

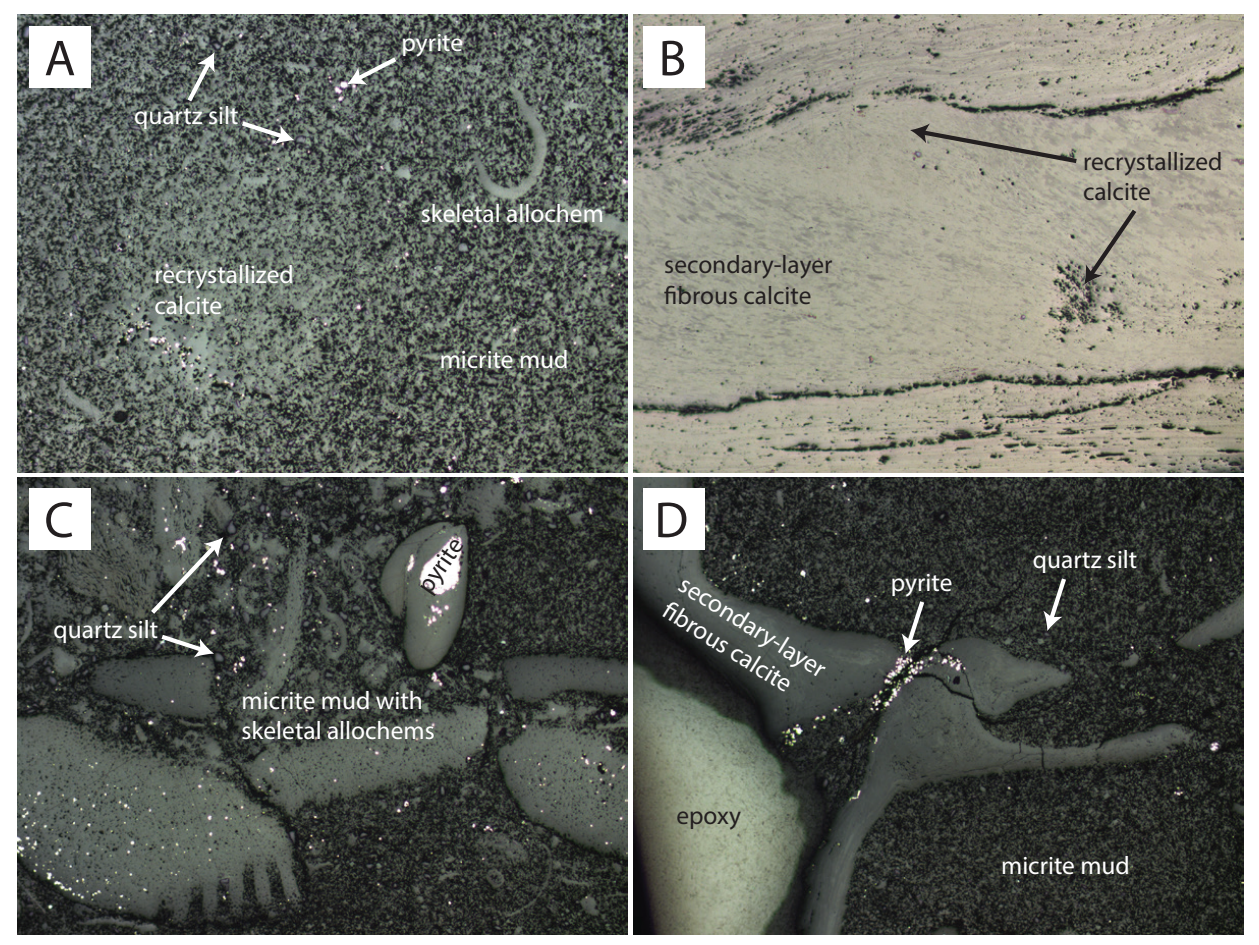




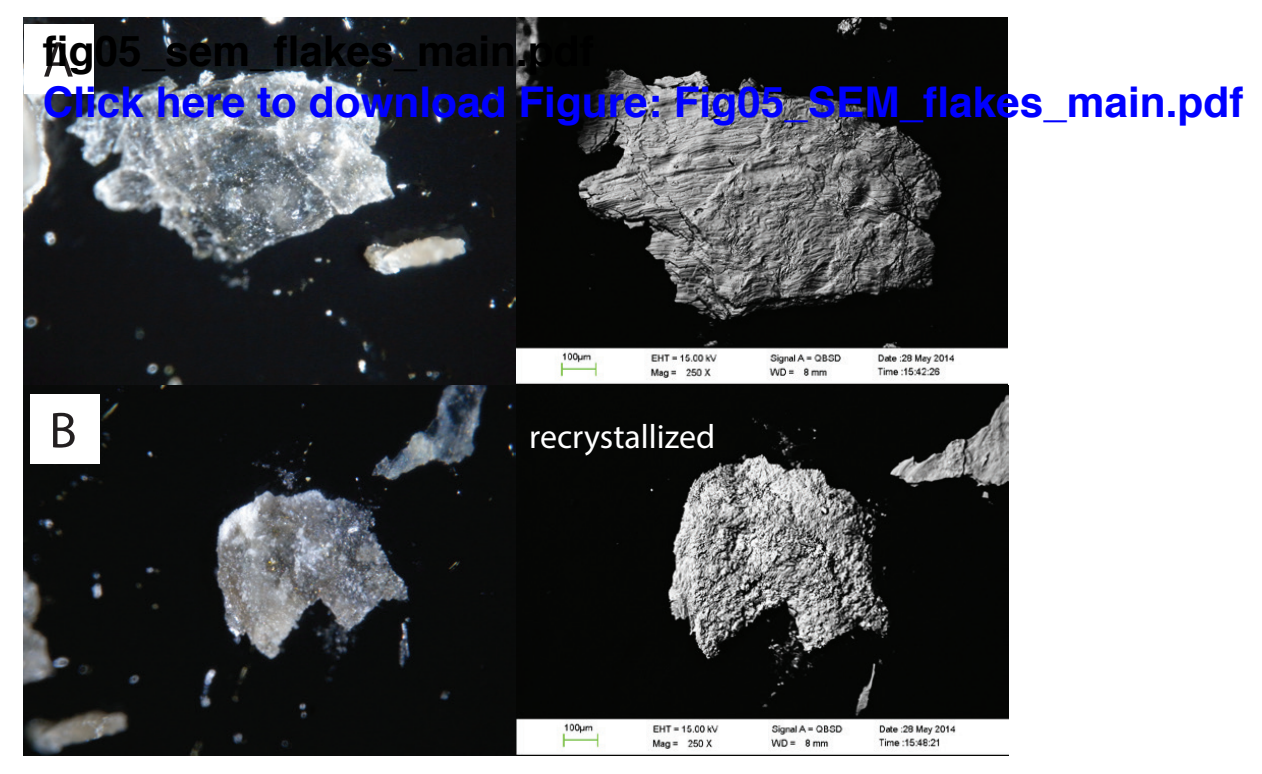




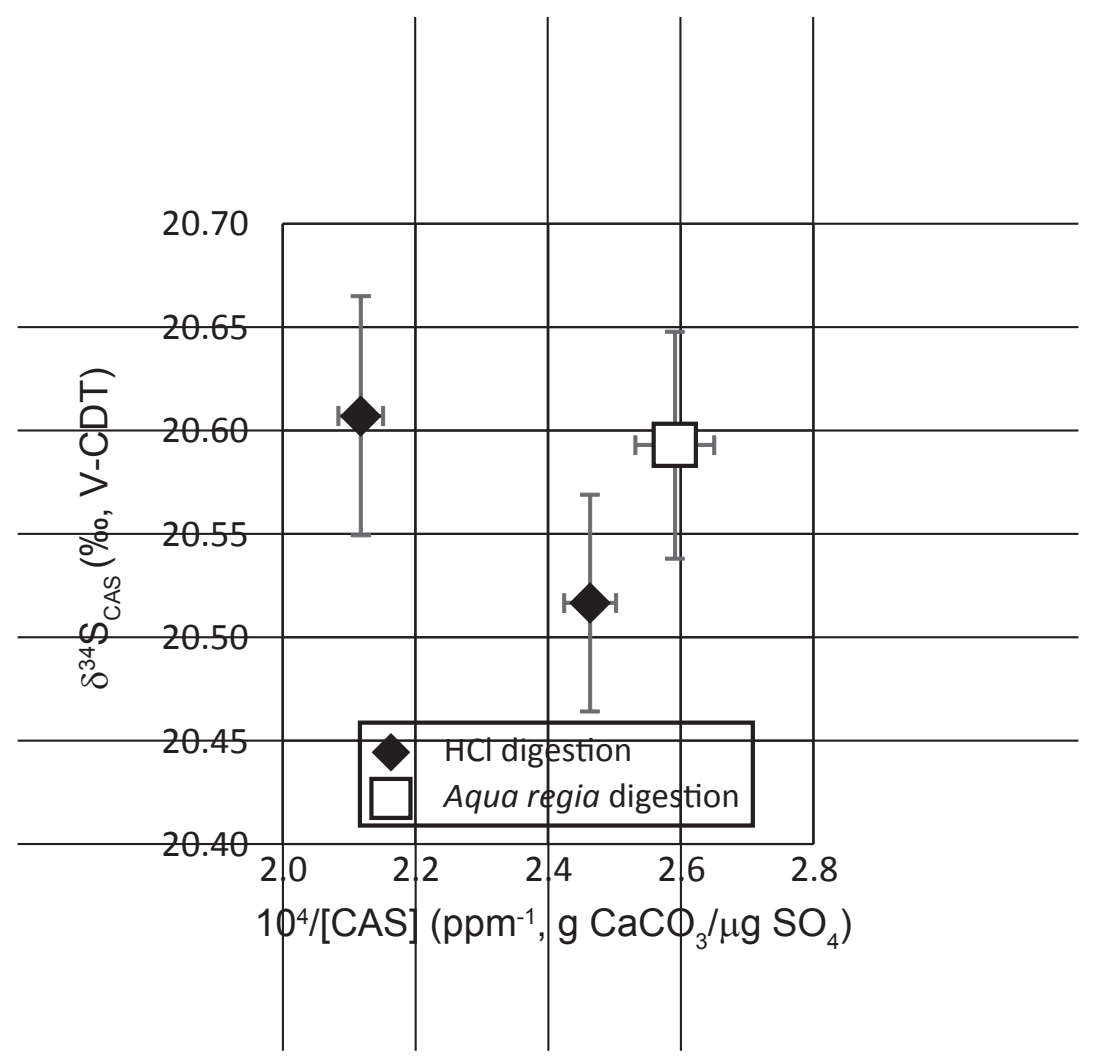




\section{fig073_eleaning_tests.pdf}

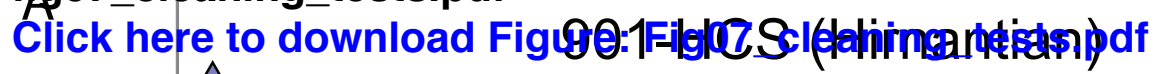

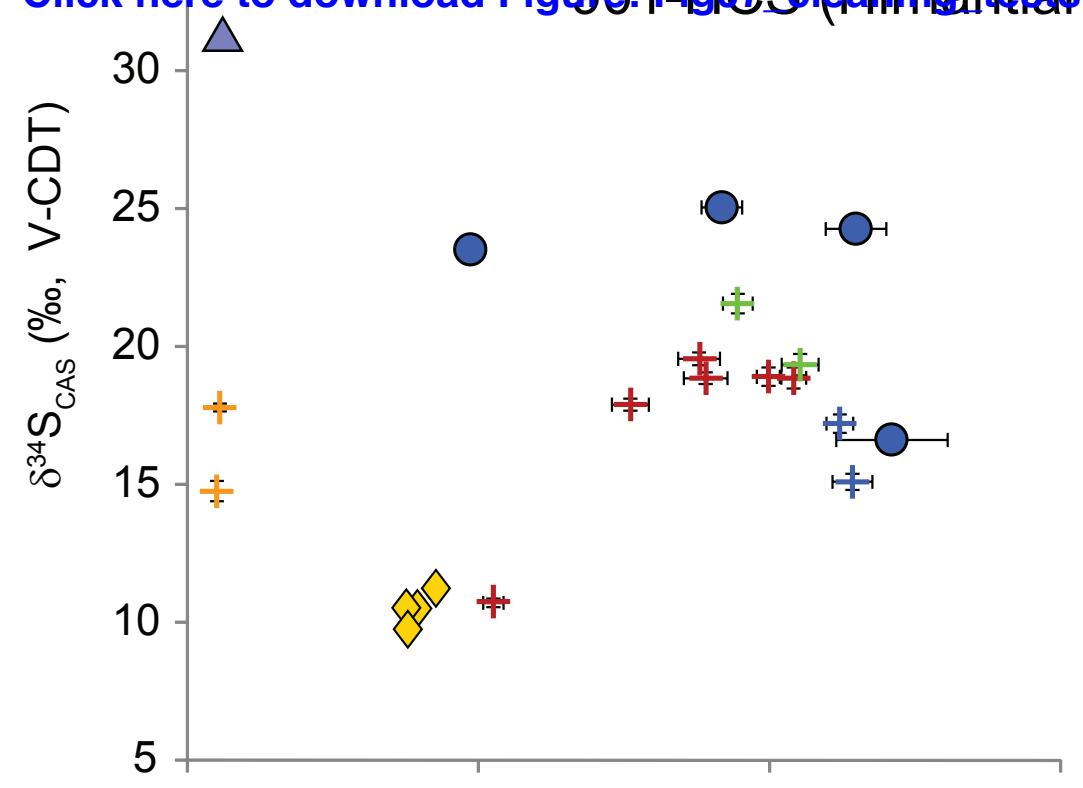$$
\text { }
$$

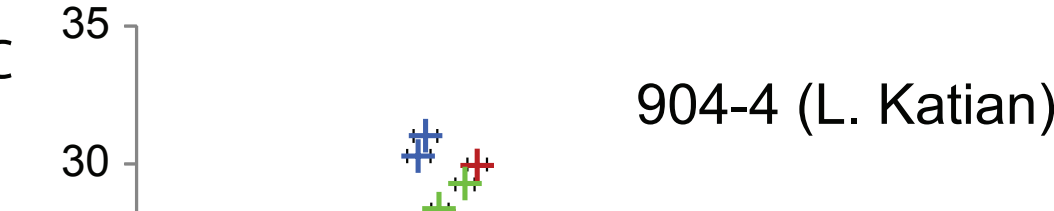

¿ 20

$25-8$

\begin{tabular}{l}
$\bigcirc$ Brachiopod \\
$\triangle$ Spar \\
\hline
\end{tabular}

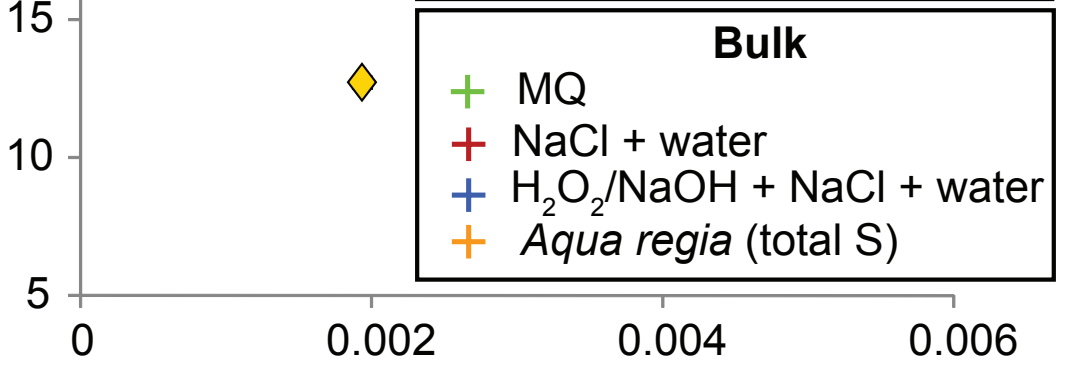

$1 /[\mathrm{CAS}]\left(\mathrm{ppm}^{-1}, \mathrm{~g} \mathrm{CaCO}_{3} / \mu \mathrm{g} \mathrm{SO}_{4}\right)$
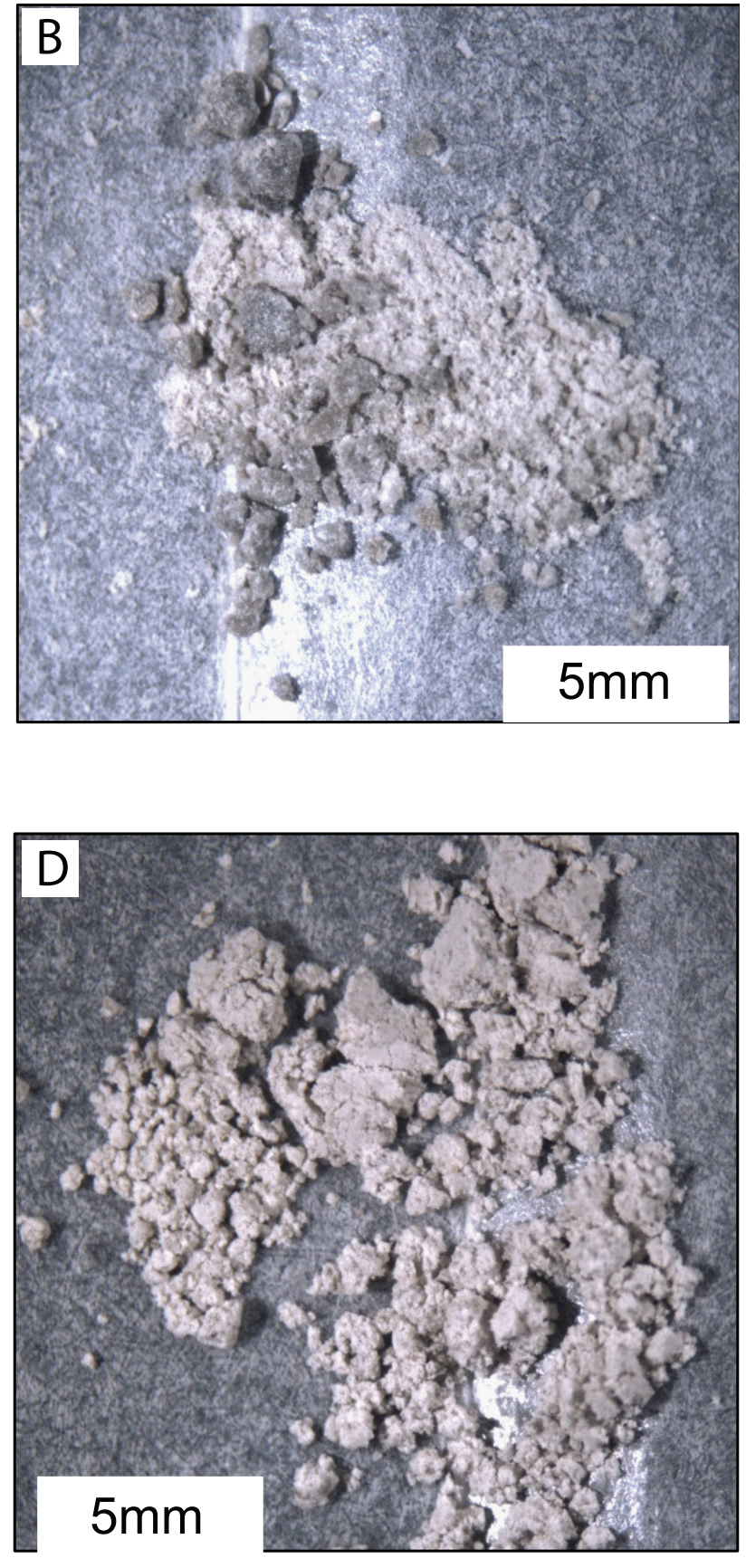
fig08 $08_{2}$ pydissexpt.pdf

Click here to download Figure: Fig08_PyDissExpt.pdf
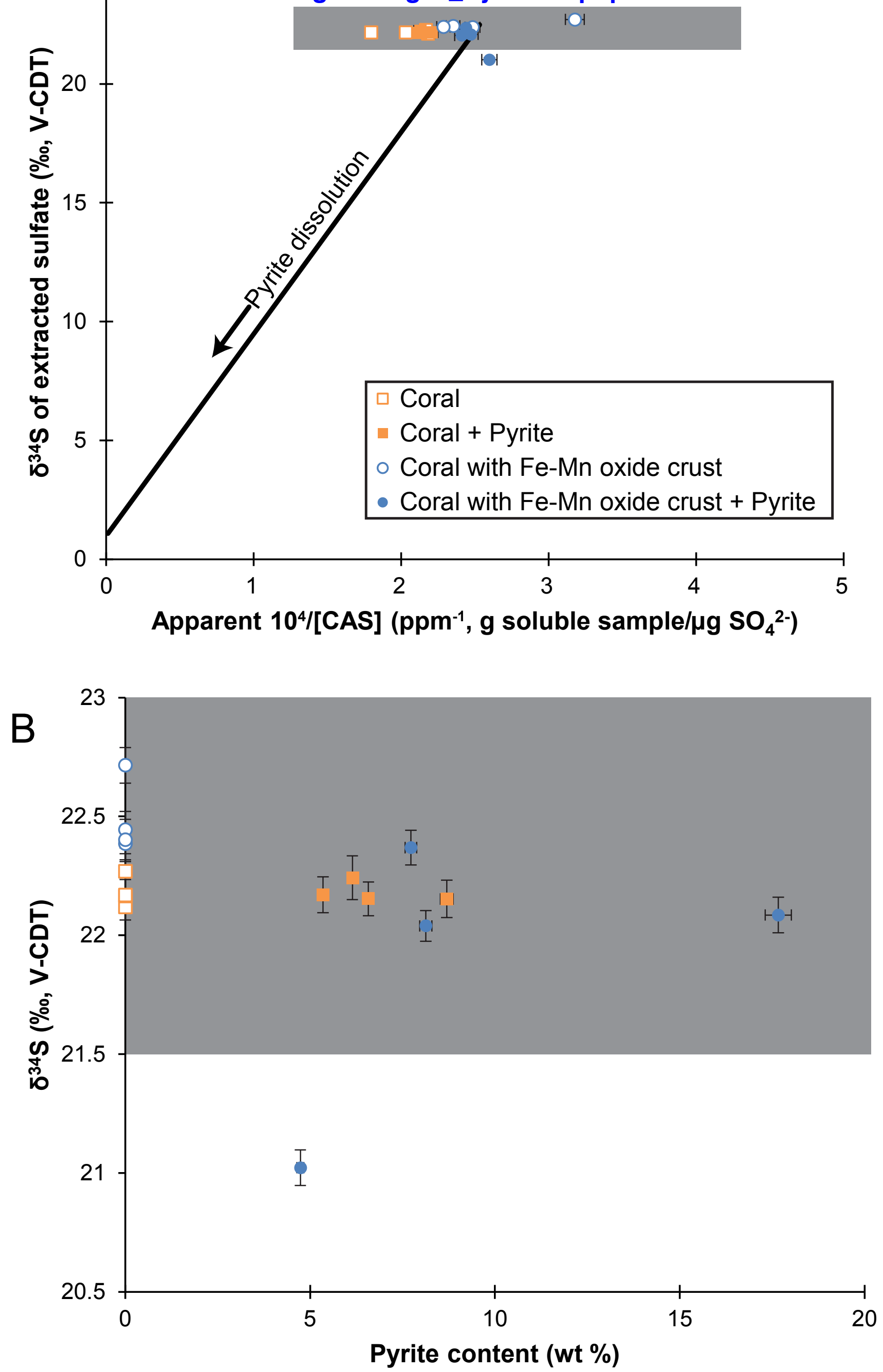


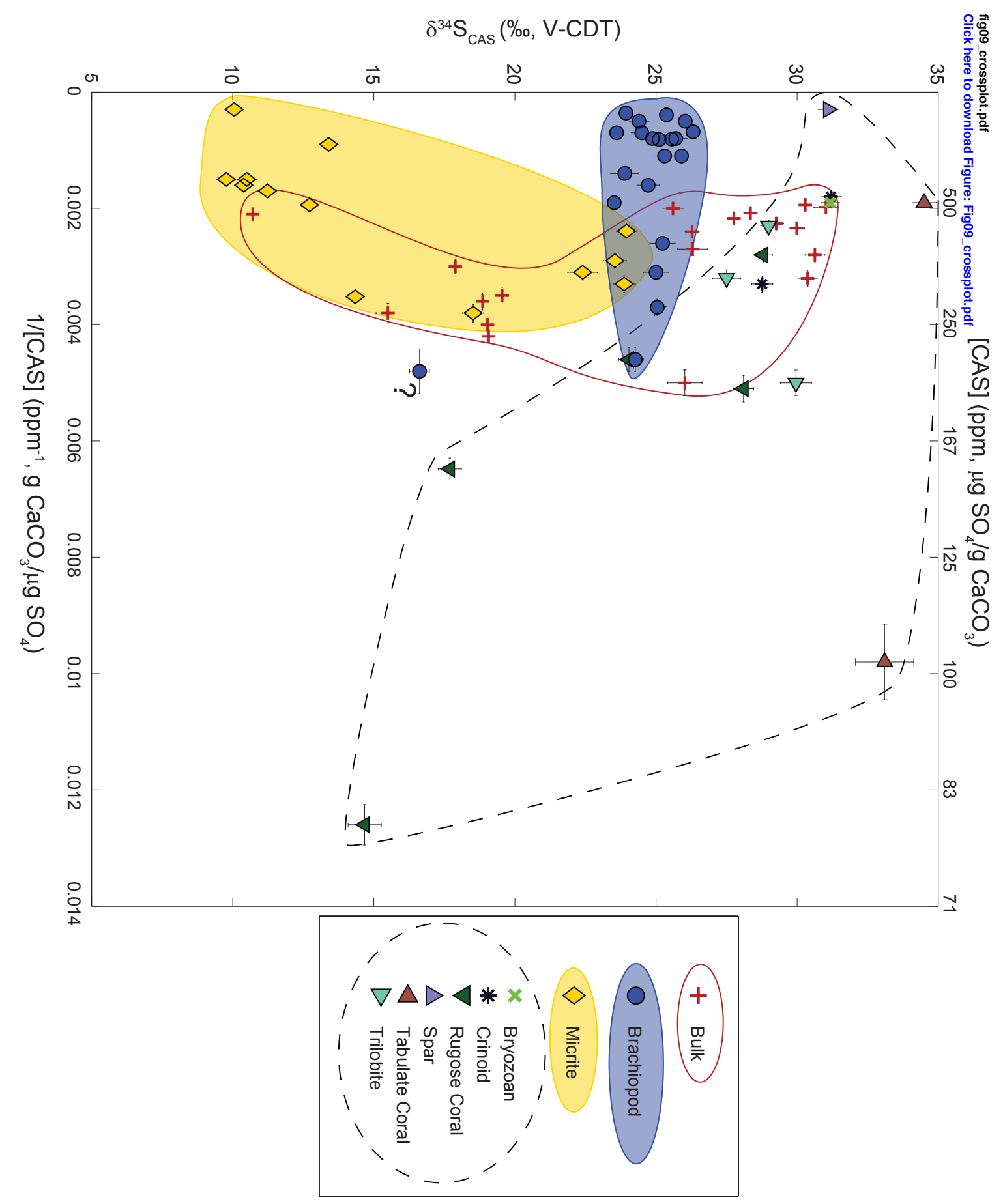




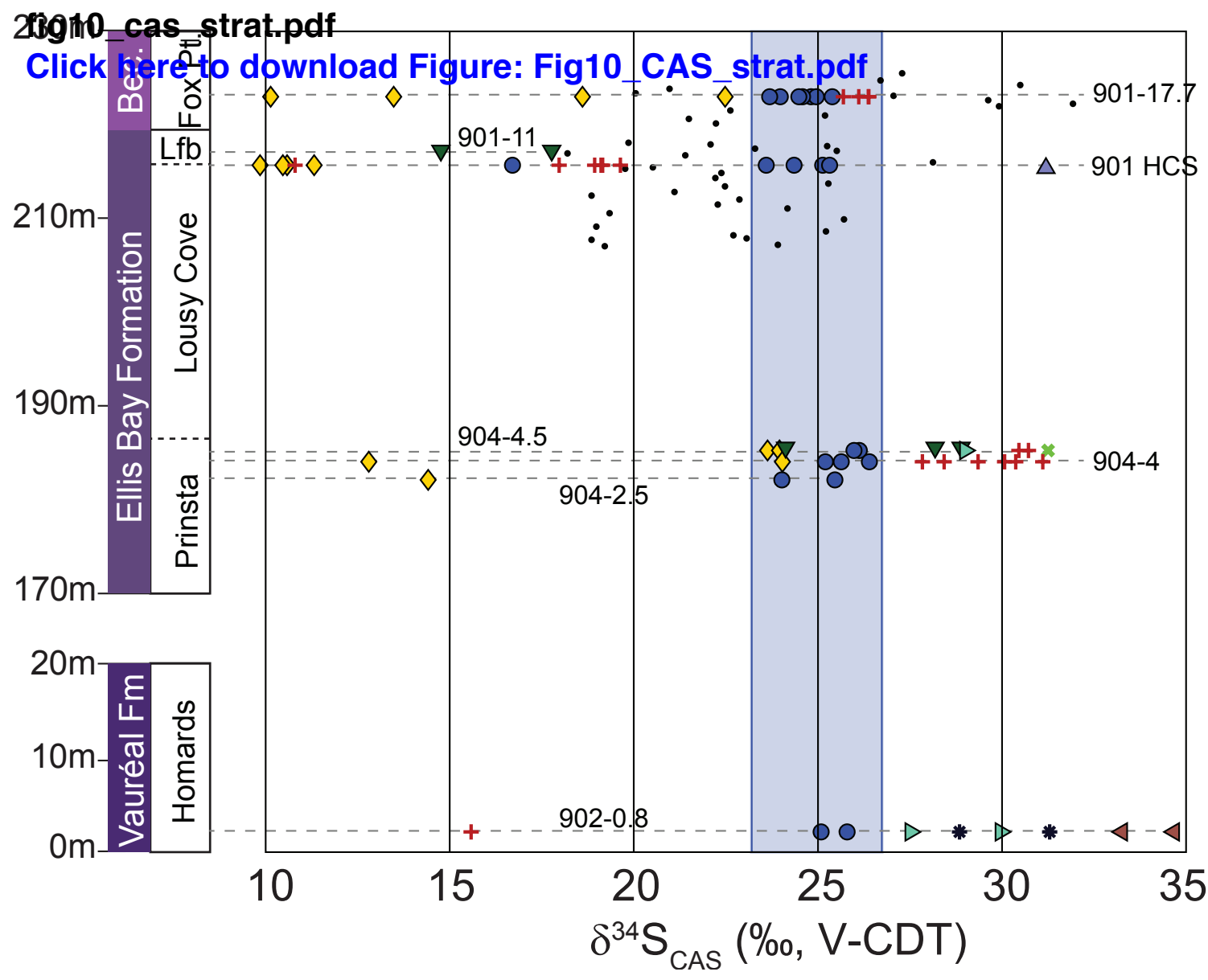

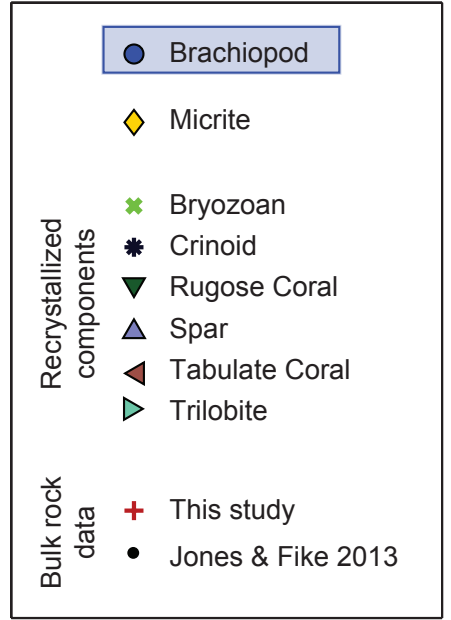


suppfig01_specimens.pdf

Click here to download Supplementary material for online publication only: SuppFig01_specimens.pdf 
suppfig02_sem_flakes.pdf

Click here to download Supplementary material for online publication only: SuppFig02_SEM_flakes.pdf 
suppfig03_coisotopes.pdf

Click here to download Supplementary material for online publication only: SuppFig03_COisotopes.pdf 